\title{
Morfologia comparada dos gêneros do grupo Merobruchus (Coleoptera: Chrysomelidae: Bruchinae): diagnoses e chave
}

\author{
José Aldir P. da Silva \& Cibele Stramare Ribeiro-Costa
}

Departamento de Zoologia, Universidade Federal do Paraná. Caixa Postal 19020, 81531-980 Curitiba, Paraná, Brasil. E-mail: aldir@ufpr.br; stra@ufpr.br

\begin{abstract}
Comparative morphology of the genera of the group Merobruchus (Coleoptera: Chrysomelidae: Bruchinae): diagnoses and key. A comparative analysis was carried out based on the detailed morphology of adults of seven genera: Caryedes Hummel, 1827, Ctenocolum Kingsolver \& Whitehead, 1974, Gibbobruchus Pic, 1913, Meibomeus Bridwell, 1946, Merobruchus Bridwell, 1946, Penthobruchus Kingsolver, 1973, and Pygiopachymerus Pic, 1911, joined in the Merobruchus group. This group is included in Acanthoscelidina Bridwell, the largest subtribe of Bruchinae, and with imprecise limits. This study describes new characters, suggests a new hypothesis for the relationships among the genera, proposes diagnoses of the group and its genera, and provides a dichotomous key. It was also possible to record Caryedes godmani (Sharp, 1885) and Caryedes Iongifrons (Sharp, 1885) for the first time from Brazil and Dioclea virgata (Rich.) Amshoff (Papilionoideae) as a new host plant for C. godmani.

KEY WORDS. Caryedes; Ctenocolum; Gibbobruchus; Meibomeus; Merobruchus; Penthobruchus; Pygiopachymerus; taxonomy.
\end{abstract}

RESUMO. Foi realizada uma análise comparativa com base na morfologia detalhada do adulto de sete gêneros: Caryedes Hummel, 1827, Ctenocolum Kingsolver \& Whitehead, 1974, Gibbobruchus Pic, 1913, Meibomeus Bridwell, 1946, Merobruchus Bridwell, 1946, Penthobruchus Kingsolver, 1973 e Pygiopachymerus Pic, 1911), reunidos no agrupamento Merobruchus. Esse grupo está incluído em Acanthoscelidina Bridwell, maior subtribo de Bruchinae, e com limites imprecisos. Este estudo possibilitou descrever novos caracteres, levantar uma nova hipótese de relacionamento entre os gêneros, e apresentar uma diagnose para o grupo e seus gêneros, além de uma chave dicotômica. Também foi possível registrar pela primeira vez para o Brasil Caryedes godmani (Sharp, 1885) e C. Iongifrons (Sharp, 1885) e Dioclea virgata (Rich.) Amshoff (Papilionoideae) como uma nova planta hospedeira para C. godmani.

PALAVRAS-CHAVE. Caryedes; Ctenocolum; Gibbobruchus; Meibomeus; Merobruchus; Penthobruchus;Pygiopachymerus; taxonomia.

Os gêneros do grupo Merobruchus pertencem a Acanthoscelidina Bridwell, maior subtribo de Bruchinae, com cerca de 800 espécies (Romero \& JoHnson 2003b, JoHnson \& RoMERo 2004, UdayagiRI \& WAdHI 1989). Desde a proposta dessa subtribo (BRIDWell 1946), existe indicação das dificuldades de estabeler seus limites. Para Borowiec (1987), os gêneros de Bruchidina considerados por BRIDWELL (1946) pertencem a Acanthoscelidina. No entanto, para outros autores, as duas subtribos são tratadas em separado (Marin \& Kingsolver 1997, Romero \& Johnson 2004).

$\mathrm{Na}$ literatura, existem indicações sobre afinidades entre sete gêneros de Acanthoscelidina, que compõem o grupo Merobruchus. WhiteheAd \& Kingsolver (1975) citaram três agrupamentos associados a subfamílias de leguminosas: 1) Merobruchus (Mimosoideae), com Merobruchus Bridwell; 2) Caryedes, com Caryedes Hummel e Meibomeus Bridwell (principalmente Papilionoideae) e 3) Gibbobruchus (Caesalpinioideae) com Gibbobruchus Pic, Penthobruchus Kingsolver e Pygiopachymerus Pic. Segundo os autores, os agrupamentos Caryedes e Gibbobruchus são grupos-irmãos e Merobruchus o grupo mais basal. Ainda dentro do grupo Caryedes, Kingsolver \& Whitehead (1974a) incluíram Ctenocolum ao descrevê-lo (Fig. 1).

No presente trabalho, são abordados os Acanthoscelidina, subtribo com limites imprecisos, a partir do estudo morfológico pormenorizado de sete gêneros que compõem o grupo Merobruchus. Com isso, foi possível apresentar também uma diagnose do grupo e de seus gêneros, além de uma chave dicotômica.

\section{MATERIAL E MÉTODOS}

Foram selecionadas 32 espécies representativas dos sete gêneros do grupo Merobruchus (Tab. I). Além da espécie-tipo de cada gênero também foram incluídas espécies congenéricas para melhor compreender a variação morfológica dentro dos gêneros.

Os exemplares foram obtidos por empréstimo de instituições, listadas a seguir, com o nome do curador e/ou intermediário do empréstimo entre parênteses: Coleção de Entomologia Pe. Jesus Santiago Moure, Departamento de Zoologia, Universi- 
Tabela I. Espécies examinadas e distribuição geográfica. Entre parênteses encontra-se o número de espécies atualmente em cada gênero. $\left({ }^{*}\right)$ Espécie-tipo, $\left(^{* *}\right)$ novo registro.

\begin{tabular}{|c|c|}
\hline Gêneros/Espécies & Distribuição Geográfica \\
\hline Caryedes Hummel, 1827 (41 espécies) & Neotropical \\
\hline C. brasiliensis (Thunberg, 1816) * & $\begin{array}{l}\text { México, Belize, Honduras, El Salvador, Nicarágua, Costa Rica, Panamá, } \\
\text { Trinidad, Guiana Francesa, Equador, Brasil, Argentina }\end{array}$ \\
\hline C. cavatus Kingsolver \& Whitehead, 1974 & México, Costa Rica, Panamá; Colômbia \\
\hline C. godmani (Sharp, 1885) & Panamá, Brasil ** \\
\hline C. helvinus (Motschoulsky, 1874) & $\begin{array}{l}\text { México, Belize, Honduras, Nicarágua, São Vicente, Costa Rica, Panamá, } \\
\text { Colômbia, Venezuela, Brasil, Peru, Bolívia. }\end{array}$ \\
\hline C. longifrons (Sharp, 1885) & Panamá, Colômbia, Brasil **, Bolívia \\
\hline C. paradisensis Kingsolver \& Whitehead, 1974 & Costa Rica, Panamá, Colômbia \\
\hline C. stenocephalus (Gyllenhal, 1839) & Costa Rica, Colômbia, Venezuela, Brasil \\
\hline C. $x$-liturus (Pic, 1931) & México, Costa Rica, Panamá, Colômbia, Venezuela, Brasil, Bolívia \\
\hline Ctenocolum Kingsolver \& Whitehead, 1974 (8 espécies) & Neotropical \\
\hline C. colburni Kingsolver \& Whitehead, 1974 & México, Guatemala, Honduras, Costa Rica \\
\hline C. janzeni Kingsolver \& Whitehead, 1974 & México, Costa Rica \\
\hline C. podagricus (Fabricius, 1801) & $\begin{array}{l}\text { México, Cuba, El Salvador, Nicarágua, Costa Rica, Tobago, Guiana, Equador, } \\
\text { Venezuela, Brasil }\end{array}$ \\
\hline C. tuberculatum (Motschoulsky, 1874) * & Costa Rica, Guatemala, México, Panamá, Venezuela \\
\hline Gibbobruchus Pic, 1913 (13 espécies) & Neártica/Neotropical \\
\hline G. cavillator (Fahraeus, 1839) & Brasil \\
\hline G. guanacaste Whitehead \& Kingsolver, 1975 & México, Jamaica, Nicarágua, El Salvador, Costa Rica, Venezuela \\
\hline G. mimus (Say, 1831) & Estados Unidos, México \\
\hline G. scurra (Boheman, 1833) & Brasil \\
\hline G. speculifer (Gyllenhal, 1833) * & Bolívia, Brasil, Paraguai, Uruguai \\
\hline Meibomeus Bridwell, 1946 (28 espécies) & Neártica/Neotropical \\
\hline M. apicicornis (Pic, 1933) & $\begin{array}{l}\text { México, Belize, Guatemala, Honduras, El Salvador, Nicarágua, Costa Rica, } \\
\text { Panamá }\end{array}$ \\
\hline M. cyanipennis (Sharp, 1885) & Belize, Guatemala, Honduras, Panamá, Colômbia, Venezuela, Brasil \\
\hline M. funebris (Boheman, 1859) & Bolívia, Brasil, Paraguai, Argentina \\
\hline M. musculus (Say, 1831) * & EUA \\
\hline M. petrolinae Silva \& Ribeiro-Costa, 2001 & Colômbia, Brasil \\
\hline M. rodneyi Romero \& Johnson, 2002 & México \\
\hline M. surrubresus (Pic, 1933) & $\begin{array}{l}\text { México, Belize, Guatemala, Honduras, El Salvador, Nicarágua, Costa Rica, } \\
\text { Trinidad, Panamá, Colômbia, Venezuela, Argentina }\end{array}$ \\
\hline Merobruchus Bridwell, 1946 (26 espécies) & Neártica/Neotropical \\
\hline M. santiagoi Ribeiro-Costa, 2007 & México, Cuba, Honduras, Costa Rica, Panamá, Brasil \\
\hline M. columbinus (Sharp, 1885) & $\begin{array}{l}\text { Guatemala, Honduras, El Salvador, Nicarágua, Costa Rica, Trinidad, Panamá, } \\
\text { Colômbia, Venezuela }\end{array}$ \\
\hline M. julianus (Horn, 1894) * & Estados Unidos, México \\
\hline M. paquetae Kingsolver, 1980 & Nicarágua, Costa Rica, Panamá, Colômbia, Suriname, Venezuela, Brasil \\
\hline M. santarosae Kingsolver, 1980 & México, Honduras, Costa Rica \\
\hline Penthobruchus Kingsolver, 1973 (2 espécies) & Neotropical \\
\hline P. germaini (Pic, 1894) * & Chile, Argentina \\
\hline Pygiopachymerus Pic, 1911 (2 espécies) & Neotropical \\
\hline P. lineola (Chevrolat, 1871) & $\begin{array}{l}\text { Haiti, Belize, Honduras, El Salvador, Nicarágua, Costa Rica, Tobago, Trinidad, } \\
\text { Panamá, Colômbia, Venezuela, Brasil }\end{array}$ \\
\hline P. theresae Pic, 1911 * & Panamá, Colômbia \\
\hline
\end{tabular}



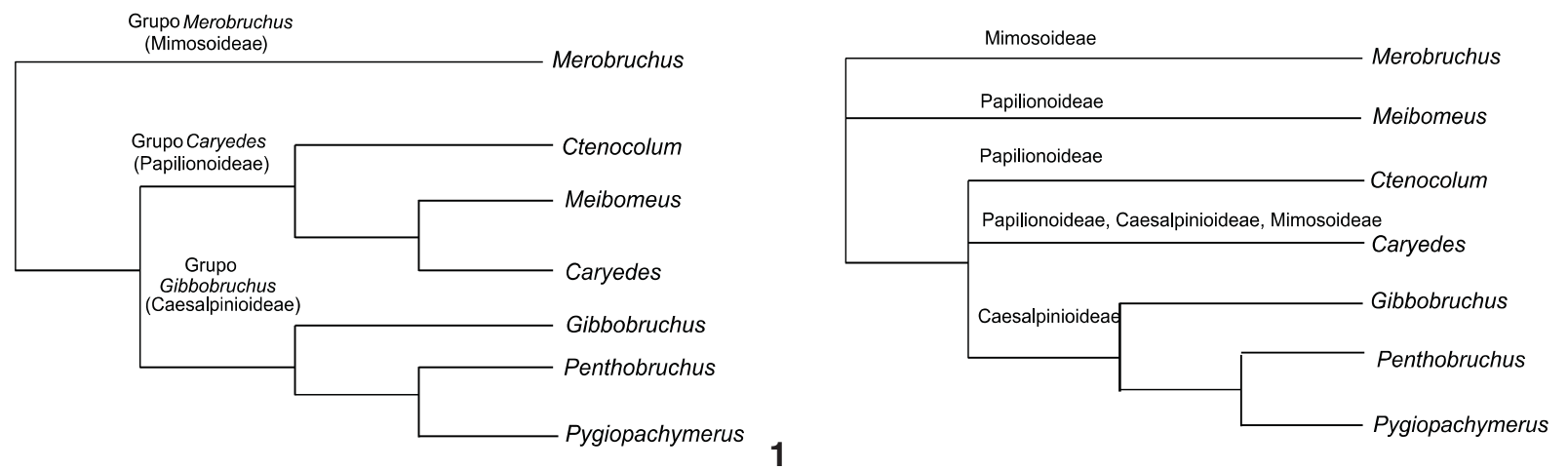

\section{1}

Figuras 1-2. Hipóteses de relacionamento entre os gêneros do grupo Merobruchus. 1) segundo KINGSOLVER \& WHITEHEAD (1974a,b, 1976), WHITEHEAD \& KinGSOLVER (1975) e Kingsolver (1988); 2) indicada pelo presente estudo.

dade Federal do Paraná, Curitiba (DZUP) (Cibele S. Ribeiro-Costa); Florida State Collection of Arthropods, Gainesville, Florida (FSCA) (John M. Kingsolver); Fundación Instituto Miguel Lillo, San Miguel de Tucumán (IMLA) (Arturo Terán); Museu de Ciências Naturais, Porto Alegre, Rio Grande do Sul (MCNZ) (Maria H.M. Galileo); Museu de História Natural do Capão da Imbúia, Curitiba (MHNCI) (Márcia Arzua); Museu Nacional, Universidade Federal do Rio de Janeiro, Rio de Janeiro (MNRJ) (Miguel A. Monné); Museu de Zoologia, Universidade de São Paulo, São Paulo (MZSP) (Sônia Casari); Texas A. \& M. University, College Station, Texas (TAMU) (Edward Riley); National Museum of Natural History, Washington D.C. (USNM) (David Furth).

A metodologia adotada para o estudo morfológico foi a de Silva \& Ribeiro-Costa (2001). No caso das peças bucais, asas e genitália da fêmea, foi seguido o trabalho de Ribeiro-Costa \& SiLVA (2003) e para a contagem de omatídios, Ribeiro-Costa (1998). A terminologia adotada foi a de Ribeiro-Costa \& Silva (2003).

As diagnoses foram feitas com base nas espécies estudadas e nos trabalhos mais relevantes sobre os gêneros (Kingsolver 1970, 1973, 1988, Kingsolver \& Whitehead 1974a, b, 1976, WhiteHEAD \& KingSOLVER 1975).

As fotos coloridas foram obtidas por uma câmara digital Sony ${ }^{\odot}$, Cyber-Shot DSC-S75, acoplada a um estereomicroscópio Zeiss Stemi 2000-c do Laboratório de Sistemática e Bioecologia de Coleoptera (Insecta), Universidade Federal do Paraná (UFPR) e as micrografias com microscópio eletrônico de transmissão, Jeol, JEM 1200 EXII, Centro de Microscopia Eletrônica, UFPR.

\section{RESULTADOS E DISCUSSÃO}

\section{Novos registros}

Com base nas etiquetas do material, registra-se pela primeira vez para o Brasil Caryedes godmani (Sharp, 1885) em sementes de Dioclea virgata (Rich.) Amshoff (Papilionoideae), novo registro de planta hospedeira para esse bruquíneo, e Caryedes longifrons (Sharp, 1885).

Material examinado. Caryedes godmani: Brasil, Pará: Carajás, VII.1986, em sementes de Dioclea virgata (Rich.) Amshoff, F. Costa leg., C.S. Ribeiro-Costa det., 6 exs (DZUP); Espírito Santo: Jacaraípe, 11-18.XI.1967, C. \& C.T. Elias leg., 1 ex. (DZUP). Caryedes longifrons: BRASIL. São Paulo: Araçatuba, Rio Jacarecatinga, X.1961, Lane \& Rabello leg., J.M. Kingsolver det., 1 ex. (FSCA).

\section{Estudo e discussão dos caracteres}

Dimensões. As maiores espécies pertencem a Caryedes (2,6-6,0 mm de comprimento; 1,6-4,6 de largura), Penthobruchus (4,5-5,0 mm de comprimento; 3,2-4,2 de largura) e Pygiopachymerus (4,7-6,1 mm de comprimento; 3,1-4,0 de largura) e as menores a Meibomeus (1,0-2,6 mm de comprimento; 0,6-1,6 de largura) e Merobruchus (1,8-6,0 mm de comprimento; 1,3-4,0 de largura). As formas intermediárias são Ctenocolum (2,0-4,5 mm de comprimento; 1,4-3,6 de largura) e Gibbobruchus (2,05,0 mm de comprimento; 1,6-3,0 de largura).

Forma do corpo. Em geral subquadrada em Caryedes, Ctenocolum, Gibbobruchus scurra, G. speculifer, Penthobruchus e Pygiopachymerus (Figs 3-9, 11, 12 e 18-20) e mais alongada em Meibomeus, Merobruchus (exceto M. julianus e M. columbinus), Gibbobruchus guanacaste e G. mimus (Figs 10, 13, 14, 16 e 17).

Pilosidade. Em geral castanha com branco, cinza e negro formando padrões variegados. Meibomeus não apresenta dorso manchado (exceto M. musculus, Fig. 14) diferindo das demais espécies. Élitros com aspecto manchado em geral nas interestrias 3, 5, 7 e 9 ocorrem em Gibbobruchus, Caryedes brasiliensis, C. paradisensis, Merobruchus boucheri (Figs 3, 6, 10 e 11), menos evidente em Caryedes stenocephalus, Merobruchus columbinus e Pygiopachymerus theresae (Figs 7, 15 e 20). Manchas irregulares no dorso ocorrem em Caryedes godmani, Ctenocolum colburni, Gibbobruchus mimus, Merobruchus julianus, M. paquetae, M. santarosae, Penthobruchus e Pygiopachymerus (Figs 4, 5, 8 e 16-19). Em Ctenocolum, além do padrão nas interestrias 3, 5, 7 e 9 (Fig. 9), há máculas irregulares no pronoto e élitros, algumas vezes sexualmente dimórficas. Pygiopachymerus lineola e Gibbobruchus mimus diferem por apresentar pilosidade rala na maior parte do dorso, apenas nas primeiras interestrias é adensada (Fig. 19). Em Meibomeus cyanipennis a pilosidade é rala (Fig. 13), mas em M. musculus, é adensada (Fig. 14). 

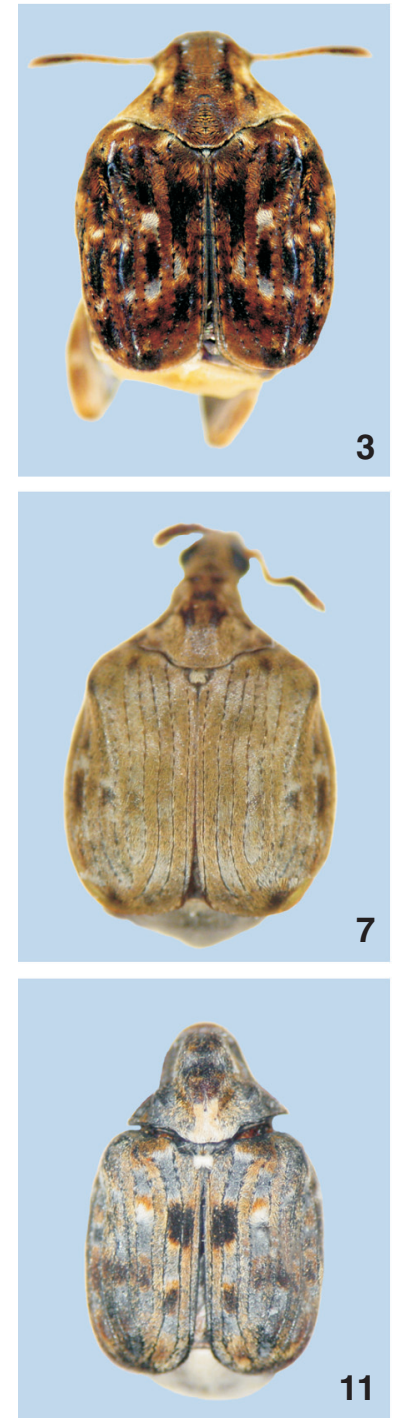
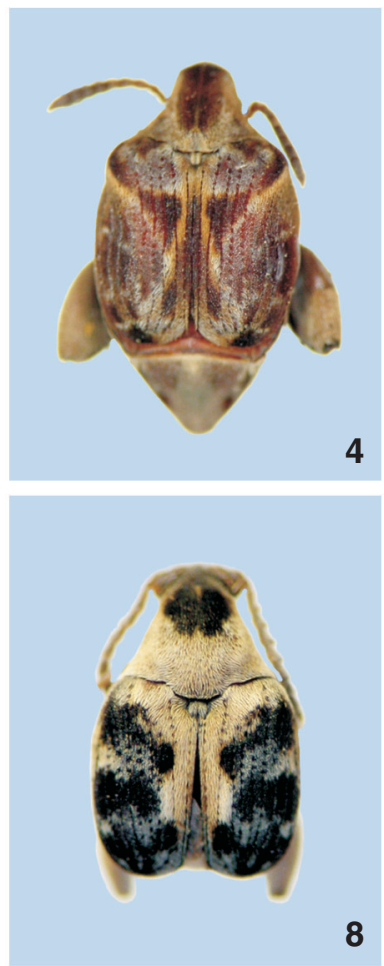

8

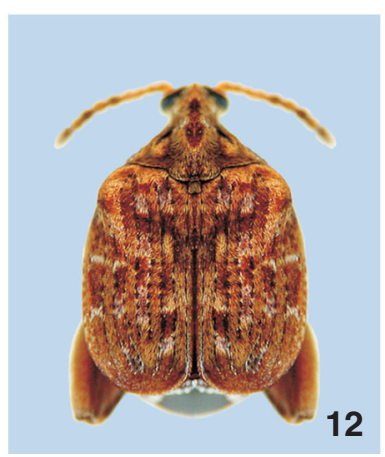

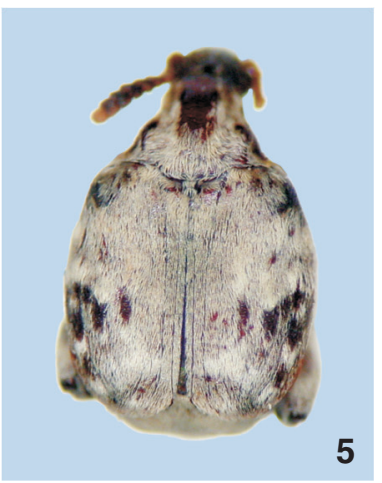
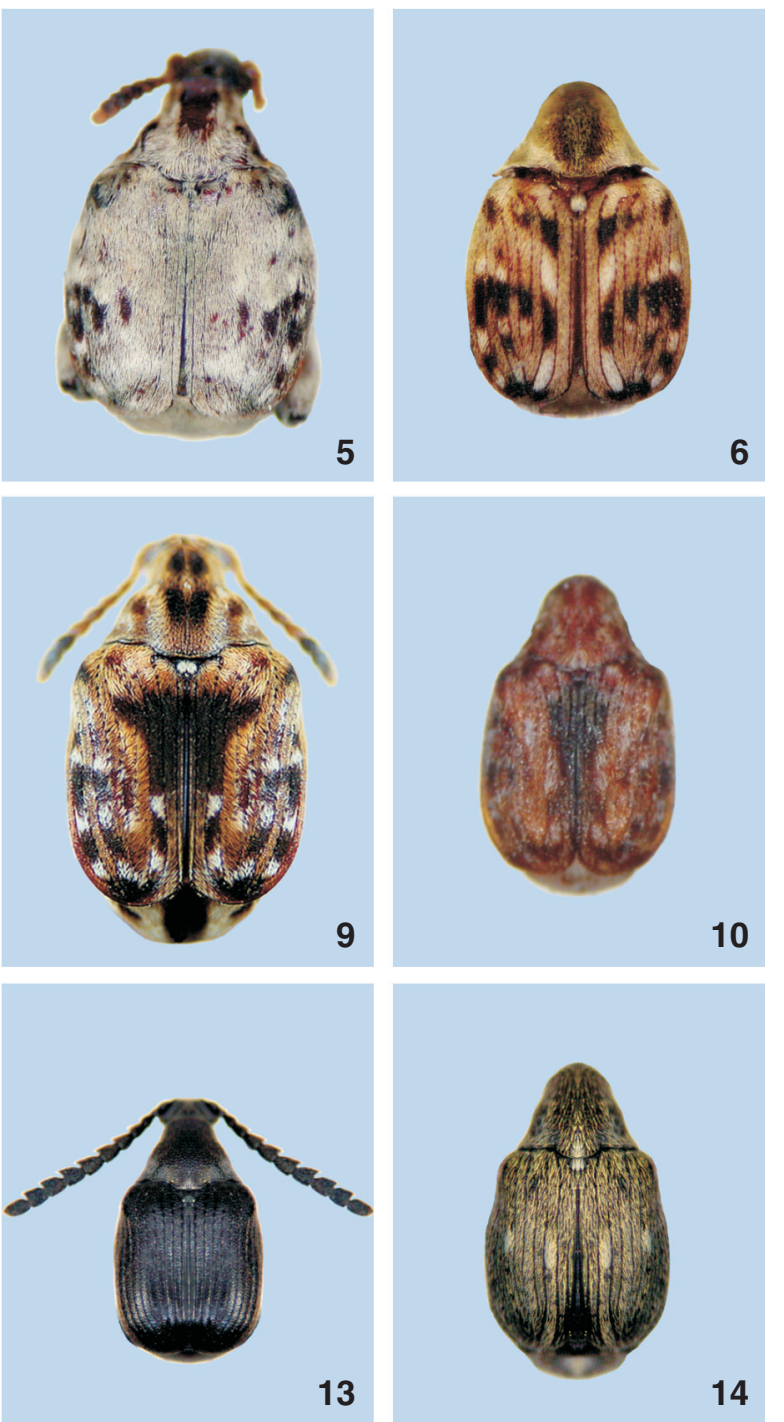

10

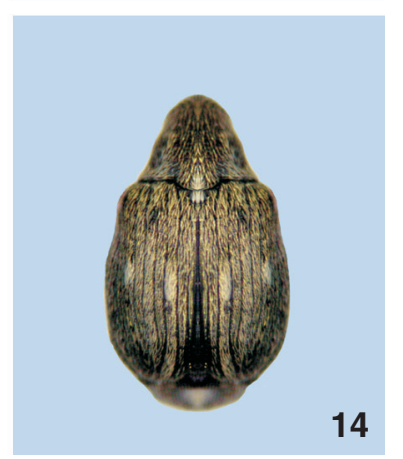

Figuras 3-14. Vista dorsal: (3) Caryedes brasiliensis; (4) C. godmani; (5) C. helvinus; (6) C. paradisensis; (7) C. stenocephalus; (8) Ctenocolum colburni; (9) C. tuberculatum; (10) Gibbobruchus mimus; (11) G. scurra; (12) G. speculifer; (13) Meibomeus cyanipennis; (14) M. musculus.

Apenas Penthobruchus e Pygiopachymerus apresentam sulco ventral do fêmur posterior glabro e polido. Esse caráter foi citado por Whitehead \& Kingsolver (1975) como indicativo de proximidade entre os dois gêneros.

Os urosternitos de Penthobruchus, Pygiopachymerus e Gibbobruchus (exceto G. speculifer) têm amplas áreas glabras, diferenciando-se de Meibomeus, em que há uma estreita faixa vertical glabra no primeiro urosternito. Segundo WhiteHEAD \& KINGSOLVER (1975) urosternitos uniformemente pilosos ocorrem no grupo speculifer de Gibbobruchus. Já em Caryedes, Ctenocolum e Merobruchus os urosternitos são uniformemente pilosos. Espécies de Caryedes também apresentam áreas glabras em outras regiões do corpo, além do abdome. Em Caryedes quadridens
(Jekel, 1855) há áreas glabras no metepisterno, em Caryedes stictocodius Kingsolver \& Whitehead, 1974 no pronoto e no metepisterno, e em Caryedes incrustatus (Gyllenhal, 1833) e Ctenocolum acapulcensis Kingsolver \& Whitehead, 1974, lateralmente nos urosternitos (Kingsolver \& WhiteheAd 1974b).

WhiteheAd \& Kingsolver (1975) comentaram que a presença de áreas glabras e polidas nos urosternitos e/ou pigídio indicam a proximidade entre os gêneros do grupo Gibbobruchus. A pilosidade no pigídio é variável entre os gêneros. Gibbobruchus e Pygiopachymerus apresentam grandes áreas glabras, e em Meibomeus é uniformemente rala (exceto $M$. musculus). Nas fêmeas de Gibbobruchus e nos machos de $G$. speculifer há uma área glabra na região mediana-apical do pigídio

Revista Brasileira de Zoologia 25 (4): 802-826, December, 2008 

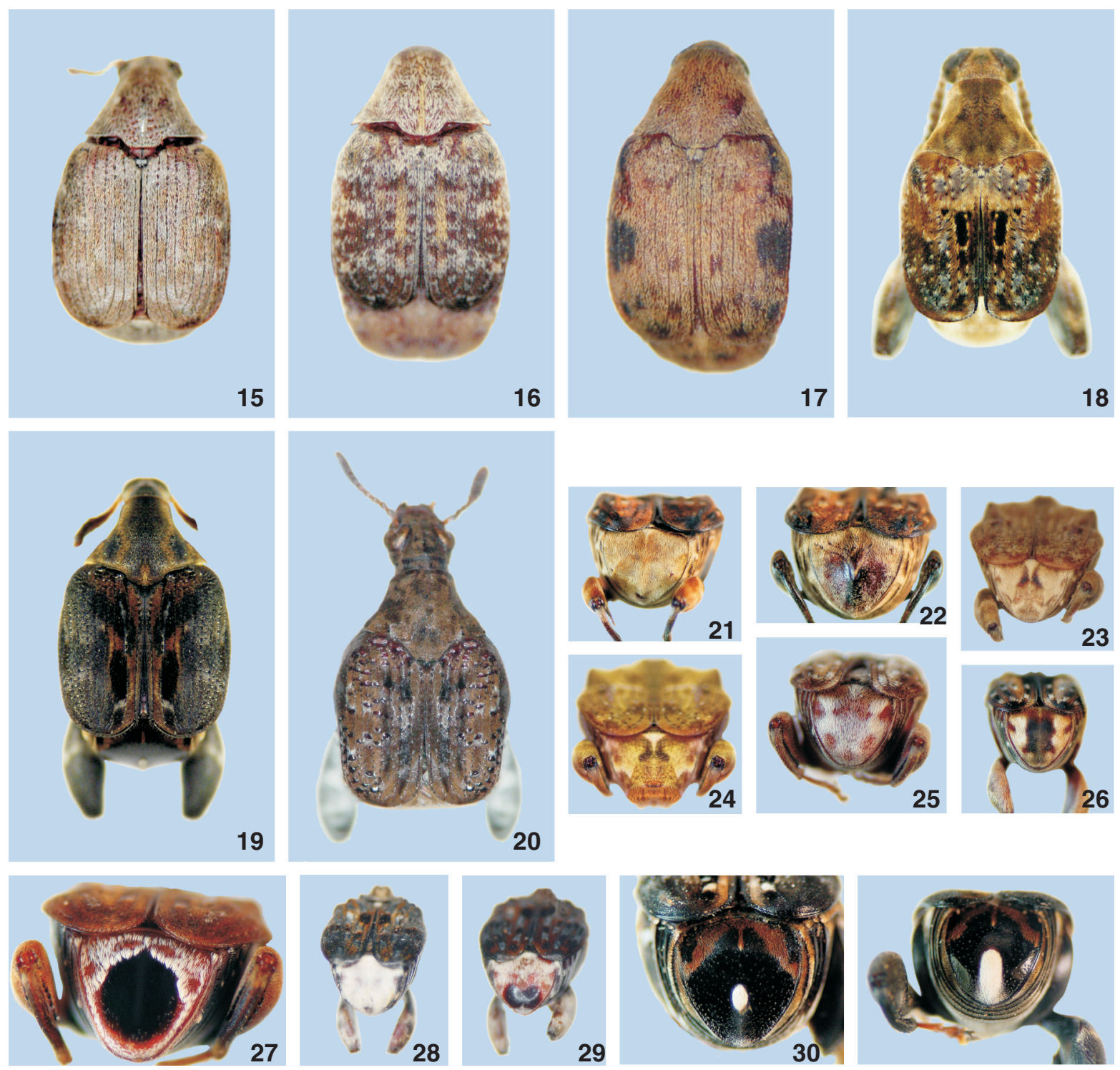

31

Figuras 15-31. Vista dorsal e pigídio. (15-20) Vista dorsal: (15) Merobruchus columbinus; (16) Merobruchus julianus; (17) Merobruchus santarosae; (18) Penthobruchus germaini; (19) Pygiopachymerus lineola; (20) Pygiopachymerus theresae. (21-31) Pigídio: (21) Caryedes brasiliensis, macho; (22) C. brasiliensis, fêmea; (23) C. cavatus, macho; (24) C. cavatus, fêmea; (25) Ctenocolum tuberculatum, macho; (26) C. tuberculatum, fêmea; (27) Gibbobruchus speculifer, macho; (28) G. scurra, macho; (29) G. scurra, fêmea; (30) Pygiopachymerus lineola, fêmea; (31) P. lineola, macho.

(Fig. 27), condição que ocorre também nos machos das espécies dos grupos polycoccus e speculifer (Whitehead \& Kingsolver 1975). Pygiopachymerus lineola diferencia-se pela presença de pequena área adensada na região mediana do pigídio das fêmeas (Fig. 30) e mediana-apical dos machos (Fig. 31).

Coloração do tegumento. Maioria das espécies de castanho a rufo. Meibomeus, Ctenocolum colburni e Pygiopachymerus, em grande parte negros (Figs 8, 13, 14 e 19). Há variações na coloração dos apêndices, principalmente antena e pernas anterior e média e, às vezes, tíbia posterior. Em geral claros, de castanho a amarelo. Meibomeus apresenta maior variação. Antena unicolor ou bicolor, quando unicolor de castanha a amarela ou inteiramente negra; quando bicolor artículos basais 1-4 claros e os demais negros. A última condição também é encontrada em Pygiopachymerus lineola. Em Meibomeus o fêmur e as tíbias anterior e média podem ser parcialmente enegrecidos;

Revista Brasileira de Zoologia 25 (4): 802-826, December, 2008 
M. cyanipennis, M. funebris e $M$. petrolinae têm o primeiro tarsômero posterior negro.

Algumas espécies de Caryedes, Ctenocolum, Gibbobruchus e Merobruchus apresentam antena com os artículos 7-9 mais escuros, porém com grande variação na tonalidade.

Cabeça. Conformação geral alongada, aproximadamente 1,5 vezes mais longa que larga (Figs 33-36 e 38-42). Extremamente alongada, cerca de 2,0 vezes mais longa que larga em Caryedes (Fig. 32) e subquadrada em Meibomeus petrolinae (Fig. 37). Em Caryedes clitoriae (Gyllenhal, 1839) é curta constituindo uma exceção para o gênero (KingSOLVER \& WHITEHEAD 1974b). Sulco transverso evidente (Figs 32-35, 39 e 40) e obsoleto em Penthobruchus, Pygiopachymerus e Meibomeus (suave em $M$. surrubresus) (Figs 36-38, 41 e 42). Fronte suavemente convexa com carena frontal, estreita (Figs 32-42), estendendo-se do vértice a sutura fronto-clipeal (Figs 33-42), exceto em Caryedes brasiliensis, que se estende até a região mediana do clípeo (Fig. 32). A presença de carena frontal é variável em Acanthoscelidina, estando presente em grande parte dos gêneros de Bruchinae (Borowiec 1987). Em Pachymerini, uma das tribos mais basais, é sempre evidente (NiLsson \& Johnson 1993, Johnson et al. 2004).

Supercílios bem definidos em Caryedes brasiliensis e Pygiopachymerus (Figs 32 e 42); escrobo maior que o comprimento da gena em Meibomeus petrolinae, M. rodneyi e M. surrubresus (Figs 37-39), menor em Merobruchus, Penthobruchus e Pygiopachymerus (Figs 40-42), e aproximadamente igual nos demais gêneros. Comprimento da gena (desde a inserção da mandíbula até o lobo inferior do olho) de Caryedes, Ctenocolum e Meibomeus cerca da metade ou maior que a menor distância entre os olhos (Figs 3234 e 36-39). Em Merobruchus, Gibbobruchus, Penthobruchus e Pygiopachymerus a gena é curta (menor que a metade da menor distância entre os olhos) (Figs 34 e 39-41). Escrobo tão ou mais longo que o diâmetro da fossa antenal e gena alongada (Figs 32 34 e 36-39), foram caracteres indicados por Whitehead \& Kingsolver (1975) para reunir Caryedes, Meibomeus e Ctenocolum no grupo Caryedes.

Gula subpentagonal (Figs 43 e 44); submento e pós-gena contíguos (Fig. 43), com leve distinção em Ctenocolum tuberculatum e Pygiopachymerus (Fig. 44).

Sinus ocular profundo, cerca de mais da metade do diâmetro do olho em vista frontal (aproximadamente a metade em Merobruchus julianus, Fig. 40). Segundo Kingsolver (2004) essa é uma característica de grupos derivados, como Acanthoscelidina; nas linhagens basais de Bruchinae, Pachymerini e Amblycerini, o sinus ocular é raso. Olhos moderadamente projetados na maioria dos gêneros; fortemente projetados em Penthobruchus (Fig. 41), Gibbobruchus speculifer (Fig. 35) e nos machos de Meibomeus petrolinae (Fig. 37).

Algumas espécies de Caryedes, Ctenocolum e Meibomeus apresentam dimorfismo sexual na cabeça (KINGSOLVER \& WHITEHEAD 1974a, b, 1976, Silva \& Ribeiro-Costa 2001). O índice ocular em geral é maior que $1 / 4$, igual ou menor em Meibomeus. Nos Caryedes, Ctenocolum e Meibomeus este índice é menor nos ma- chos e maior nas fêmeas. Em machos de algumas espécies de Meibomeus além do índice ocular, o dimorfismo é acentuado pelos olhos proeminentes lateralmente e grossamente facetados (Kingsolver \& Whitehead 1976, Silva \& Ribeiro-Costa 2001). Olhos do macho grossamente facetados ocorrem também em Megacerus Fahraeus, 1839, algumas espécies de Acanthoscelides, e em Pachymerini em geral (NiLsson \& Johnson 1993).

O número de omatídios após o ápice do sinus ocular varia entre 3 a 6 em Meibomeus, enquanto nos demais gêneros varia de 5-10; lobo pós-ocular em geral é estreito (Fig. 46), sendo usualmente muito longo em Caryedes e Pygiopachymerus (Fig. 45). Lobo inferior do olho aproximadamente com a mesma largura que o superior, exceto em Caryedes brasiliensis, Meibomeus musculus e $M$. rodneyi, em que o inferior é cerca da metade da largura do superior (Figs 32, 36 e 38).

Antena geralmente curta (menor que o comprimento do élitro), igual ou tão longa quanto o élitro em Ctenocolum, Meibomeus cyanipennis, M. musculus e M. surrubresus. Em M. cyanipennis e M. surrubresus, mais longa nos machos. Em geral denteadas (Fig. 50) com artículos subapicais gradualmente dilatados (Fig. 52) podendo formar uma clava (Fig. 47). Antenas serreadas ocorrem em Caryedes longifrons e Meibomeus (Fig. 51). Nos machos de Caryedes godmani (Fig. 48) a antena é fortemente flabelada e nas fêmeas os artículos apicais são fracamente flabelados (Figs 49). Penthobruchus, Gibbobruchus speculifer, Meibomeus cyanipennis e M. surrubresus (Figs 50 e 51) apresentam pedicelo com cerca da metade do comprimento do escapo.

Em Gibbobruchus, segundo Whitehead \& Kingsolver (1975), a antena dos machos de G. polycoccus Fahraeus, 1839 é flabelada e a das fêmeas serreada. Das espécies estudadas de Caryedes, apenas C. godmani apresenta dimorfismo (Figs 48 e 49), mas segundo Kingsolver \& WHITEHEAD (1974b) isso ocorre em outras espécies do gênero. Em Ctenocolum, a antena do macho é mais longa (Kingsolver \& Whitehead 1974a). No presente estudo, as antenas são tão ou mais longas que o comprimento dos élitros, em ambos os sexos.

Labro subretangular, lados arredondados e ápice truncado (Figs 32-42); mandíbulas simétricas, ápice agudo, cerdas esparsas subapicais (Figs 53 e 56), prosteca presente, mola com dentes formando área de trituração (KINGSOLVER 2004). Ctenocolum, Caryedes (exceto C. godmani e C. x-liturus), Merobruchus, Penthobruchus e Pygiopachymerus têm dentes pouco desenvolvidos (Figs 60 e 61). Em Caryedes brasiliensis há dentículos uniformemente distribuídos (Figs 56-57). Dentes desenvolvidos e mais adensados no ápice da mola são encontrados em Gibbobruchus e Meibomeus (Figs 58 e 59). Em Gibbobruchus speculifer, o ápice dos dentes são mais arredondados e em maior número na região apical (Fig. 58) quando comparados aos de Caryedes godmani, C. x-liturus e Meibomeus, que são mais agudos (Fig. 59). Marthur \& Dhadial (1963) ilustraram dentes na mola de Caryedon serratus (Olivier, 1790) e SINGH (1981b, 1986) de Bruchus Linnaeus, 1767, Bruchidius Schilsky, 1905, Callosobruchus Pic, 1902 e Specularius Bridwell, 1938.

Revista Brasileira de Zoologia 25 (4): 802-826, December, 2008 


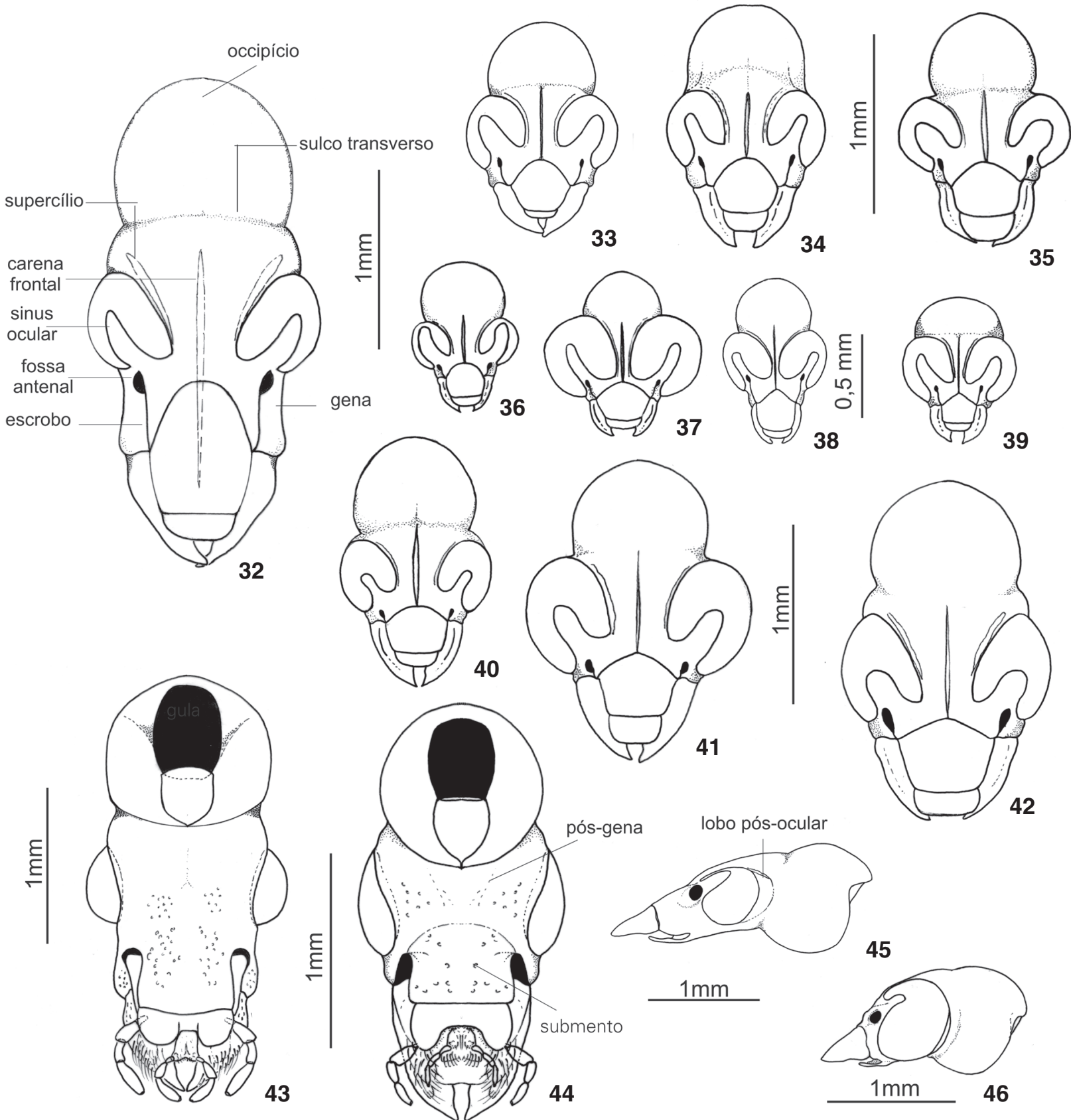

Figuras 32-46. Cabeça. Vista frontal (32-42): (32) Caryedes brasiliensis; (33) Ctenocolum janzeni; (34) C. tuberculatum; (35) Gibbobruchus speculifer; (36) Meibomeus musculus; (37) M. petrolinae; (38) M. rodneyi; (39) M. surrubresus; (40) Merobruchus julianus; (41) Penthobruchus germaini; (42) Pygiopachymerus lineola. (43-44) Vista ventral: (43) Caryedes brasiliensis; (44) Pygiopachymerus lineola. (45-46) Vista lateral: (45) Caryedes brasiliensis; (46) Penthobruchus germaini.

Maxila com cardo afilado e longo (Fig. 54); mediostipe sem área esclerotinizada; palpo maxilar com setas esparsas (Fig. 62), quarto segmento maior que os demais e ápice com sensilas; gálea e lacínia em lobos distintos, a gálea com anel esclerotiniza- do na base (Fig. 54). Caryedes, Ctenocolum, Gibbobruchus, Meibomeus e Merobruchus apresentam gálea com cerdas simples e espatuladas (Figs 63 e 64). As cerdas espatuladas de Ctenocolum tuberculatum diferem das demais espécies pelo ápice mais dila- 

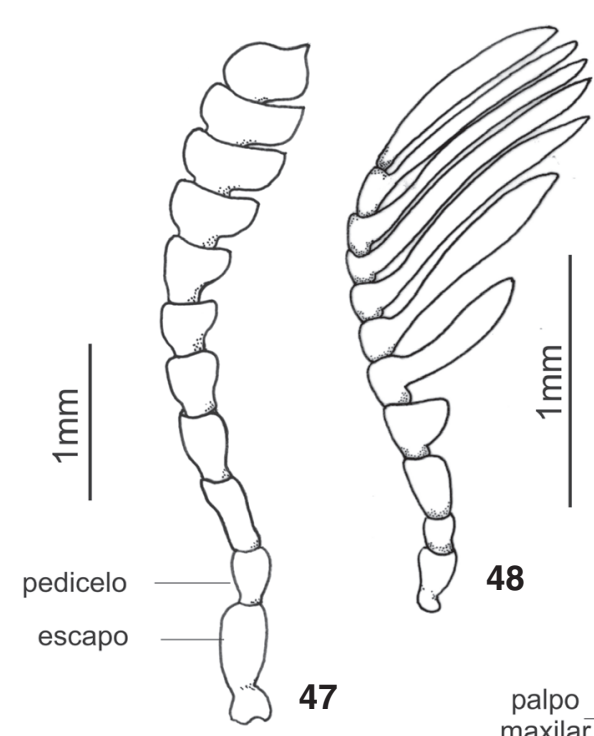

48
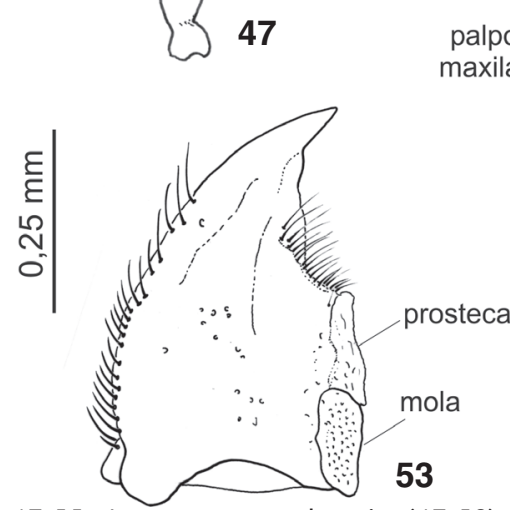

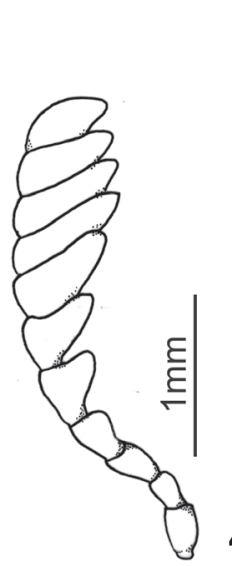

49

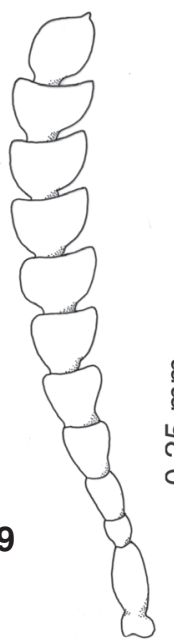

50

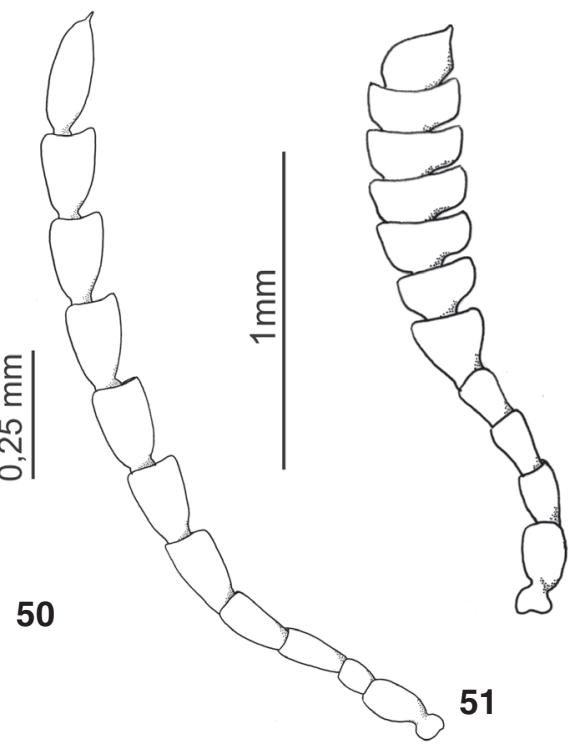

52

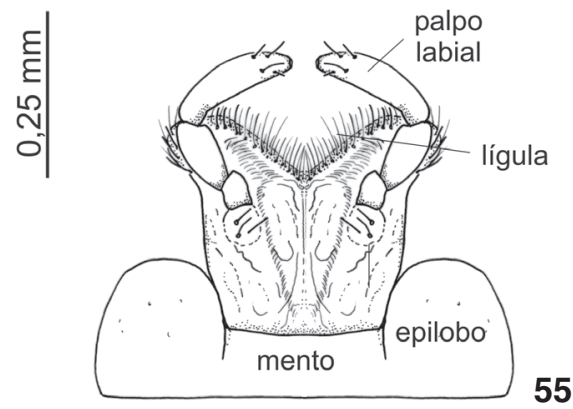

Figuras 47-55. Antena e peças bucais. (47-52) Antena: (47) Caryedes brasiliensis, macho; (48) C. godmani, macho; (49) C. godmani, fêmea; (50) Gibbobruchus speculifer, macho; (51) Meibomeus surrubresus, macho; (52) Pygiopachymerus lineola. (53-55) Peças bucais de Caryedes brasiliensis: (53) mandíbula; (54) maxila; (55) lábio.

tado e presença, em uma das superfícies, de cerdas mais curtas e largas (Fig. 65). São semelhantes as de Pseudopachymerina spinipes (Erichson, 1833) (TERÁn 1962: fig. 10). Penthobruchus e Pygiopachymerus se distinguem dos demais gêneros por compartilharem cerdas simples (Fig. 66). Esse tipo de cerda também foi encontrado em Acanthoscelides obtectus Say, 1831 (Daviault 1928) e Caryedon serratus (Olivier, 1790) (MarThur \& Dhadial 1963). Para Terán (1962: fig. 102) a maxila de Penthobruchus germaini, apresenta cerdas espatuladas. As modificações das cerdas da gálea e lacínia ocorrem provavelmente em função da coleta de diferentes tipos de grãos de pólen (Kingsolver 2004).

Mento com dois epilobos (Fig. 55), palpos labiais com três segmentos e cerdas esparsas (Figs 55 e 67), palpífero não evidente. Lábio em vista interna com depressão mediana, margens laterais convergentes e cerdas raramente paralelas (Meibomeus surrubresus Fig. 68). Lígula emarginada, algumas vezes suave (Fig. 68), e mais acentuada em Caryedes brasiliensis (Fig. 55).
Tórax. Pronoto campaniforme, truncado ou levemente arredondado na margem anterior e sinuoso na posterior; comprimento cerca de 1,5 vezes a sua maior largura (Figs 69-72); margens laterais de Caryedes, Gibbobruchus e Pygiopachymerus fortemente côncavas (Figs 69 e 71) e em Caryedes paradisensis, Ctenocolum, Gibbobruchus mimus, Meibomeus, Merobruchus e Penthobruchus, quase retas (Figs 70 e 72). Disco homogeneamente foveolado em Caryedes paradisensis, Ctenocolum podagricus, Meibomeus e Merobruchus. Em cada fóvea, há uma cerda próxima da margem anterior (Fig. 81). Algumas espécies de Merobruchus com fovéas conspícuas no disco. Geralmente Caryedes, Ctenocolum, Pygiopachymerus, Penthobruchus, apresentam fóveas esparsas geralmente nos terços laterais do pronoto.

Gibosidade mediana do pronoto conspícua em Ctenocolum (pouco elevada em C. podagricus e ausente em C. colburni), e Gibbobruchus (exceto G. mimus) (Figs 74 e 80); ausente ou presente e conspícua em Caryedes; ausente em Meibomeus, Merobruchus, Penthobruchus e Pygiopachymerus (Figs 73 e 75). Em Ctenoco- 

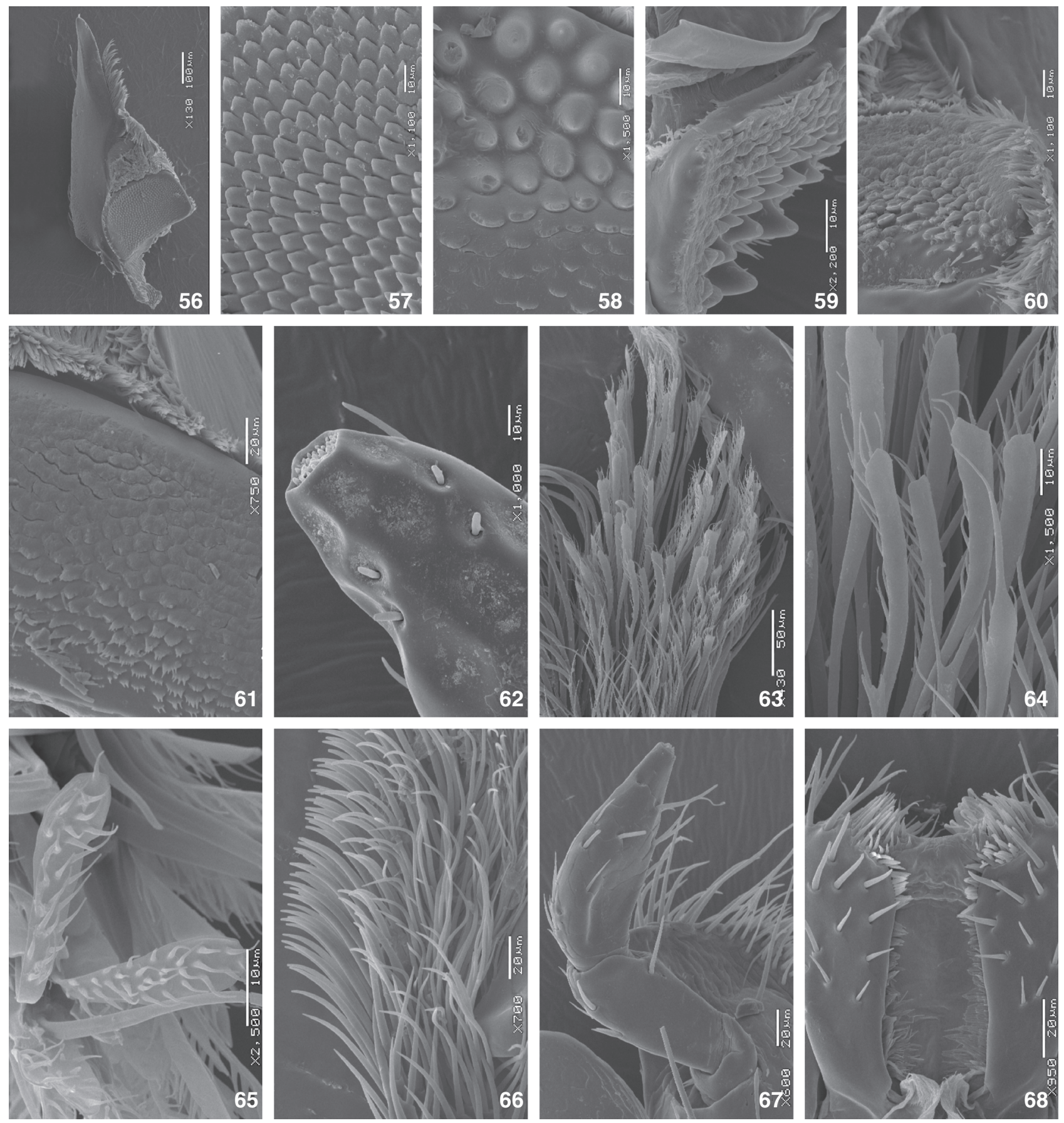

Figuras 56-68. Mandíbula, maxila e lábio. (56-61) Mandíbula: (56) Caryedes brasiliensis, vista interna; (57) C. brasiliensis, mola; (58) Gibbobruchus speculifer, mola; (59) Meibomeus apicicornis, mola; (60) Ctenocolum tuberculatum; (61) Pygiopachymerus lineola, mola. (6266) Maxila: (62) Caryedes brasiliensis, palpo maxilar; (63) C. brasiliensis, cerdas da gálea; (64) C. brasiliensis, detalhe das cerdas da gálea; (65) Ctenocolum tuberculatum, cerdas da gálea; (66) Pygiopachymerus lineola, cerdas da gálea. (67-68) Lábio: (67) Gibbobruchus speculifer, palpo labial; (68) Meibomeus surrubresus, vista interna.

Revista Brasileira de Zoologia 25 (4): 802-826, December, 2008 


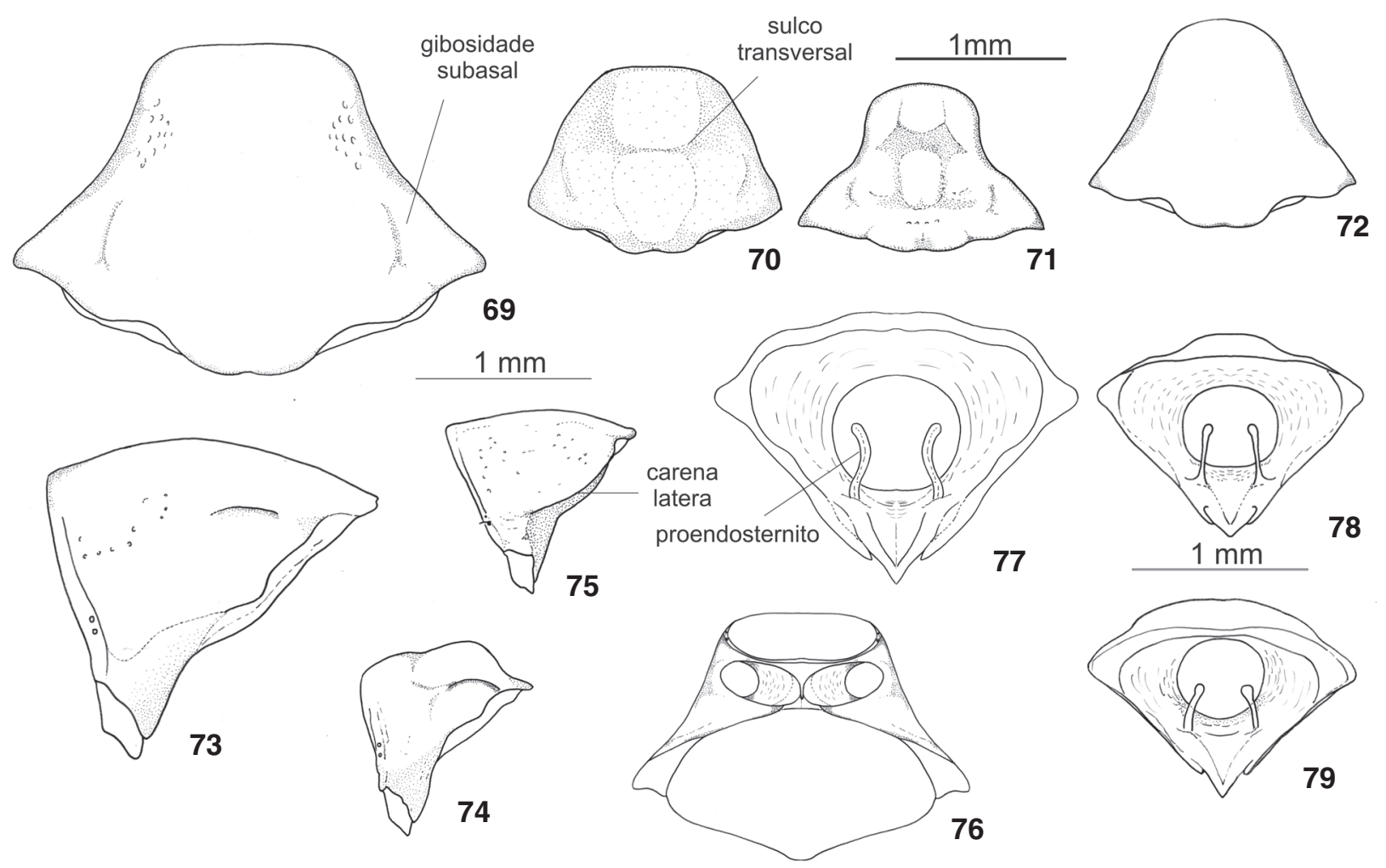

Figuras 69-79. Protórax. (69-72) Pronoto: (69) Caryedes brasiliensis; (70) Ctenocolum tuberculatum; (71) Gibbobruchus speculifer; (72) Merobruchus julianus; (73-75) vista lateral: (73) Caryedes brasiliensis; (74) Gibbobruchus speculifer; (75) Merobruchus julianus. (76) Prosterno de Caryedes brasiliensis. (77-79) Endosternitos: (77) Caryedes brasiliensis; (78) C. cavatus (79); Merobruchus julianus.

lum e Gibbobruchus usualmente dividida por sulco transversal (Figs 70 e 74); em Caryedes helvinus e Caryedes stenocephalus há um sulco mediano longitudinal. Gibosidade subasal do pronoto em Ctenocolum e Gibbobruchus freqüentemente proeminente, conspícua (Fig. 74) (pouco elevada em G. guanacaste e G. mimus), em Meibomeus e Merobruchus é muito pouco elevada, obsoleta e em Caryedes brasiliensis é pouco elevada (Fig. 69) quando comparada a de C. stenocephalus.

Gibosidades no pronoto ocorrem em Decellebruchus Borowiec, 1987, Horridobruchus Borowiec, 1987, Kingsolverius Borowiec, 1987, Meganeltumius Romero \& Johnson, 2003, Neltumius Bridwell, 1946, Pseudopachymerina Zacher, 1952 e Specularius (Kingsolver 1964, Borowiec 1987, Romero \& Johnson 2003a, b).

Carena lateral ausente, ou muito obsoleta (Fig. 74). Raramente alcança a metade do comprimento do protórax como em Merobruchus boucheri, M. paquetae e M. julianus (Fig. 75). Em Ctenocolum tuberculatum e C. podagricus é curta, pouco evidente e em Caryedes brasiliensis (Fig. 73) e C. x-liturus, há vestígio de carena. A carena lateral em Acanthoscelidina é muito variável, contudo é constante em Pachymerini e Amblycerini (Borowiec 1987), grupos basais de Bruchinae (Johnson \& Romero 2004). Para Kingsolver (2004) há uma tendência evolutiva de modificação ou perda da carena em grupos mais derivados como Acanthoscelidina.

Prosterno estreito, com ápice afilado; cavidades coxais elípticas, fechadas (Fig. 76). Escutelo de subquadrado a retangular, com ápice inteiro ou leve emarginação é encontrado em Caryedes, Meibomeus cyanipennis e Pygiopachymerus e com ápice bidentado em Gibbobruchus, Ctenocolum, Merobruchus e Meibomeus. Geralmente em Acanthoscelidina o escutelo é subquadrado com ápice bidentado (Borowiec 1987); ápice inteiro ocorre principalmente em Pachymerini (NiLsson \& JoHnson 1993), grupo basal de Bruchinae (JoHnson \& Romero 2004).

Élitros com áreas rugosas na margem anterior e região basal das interestrias ocorrem apenas em Pygiopachymerus (Fig. 93). Cada élitro com 10 estrias constituídas por pontos coalescentes (Figs 82 e 83); pontos isolados e alinhados evidentes em Penthobruchus e Caryedes godmani (Figs 85 e 92). Apenas nas espécies de Meibomeus, M. apicicornis, M. cyanipennis, M. funebris e M. musculus, a estria 4 é mais curta que a 3 e a 5 na base partindo de um dente inconspícuo (Fig. 89), característica utilizada por Bridwell (1946), além do pécten, para definir Meibomeus, separando-o em chave, de Acanthoscelides, Merobruchus e Algarobius Bridwell, 1946. Em Meibomeus petrolinae, M. rodneyi e Merobruchus, as estrias 1-7 iniciam-se muito próximas à margem basal (Figs 88 

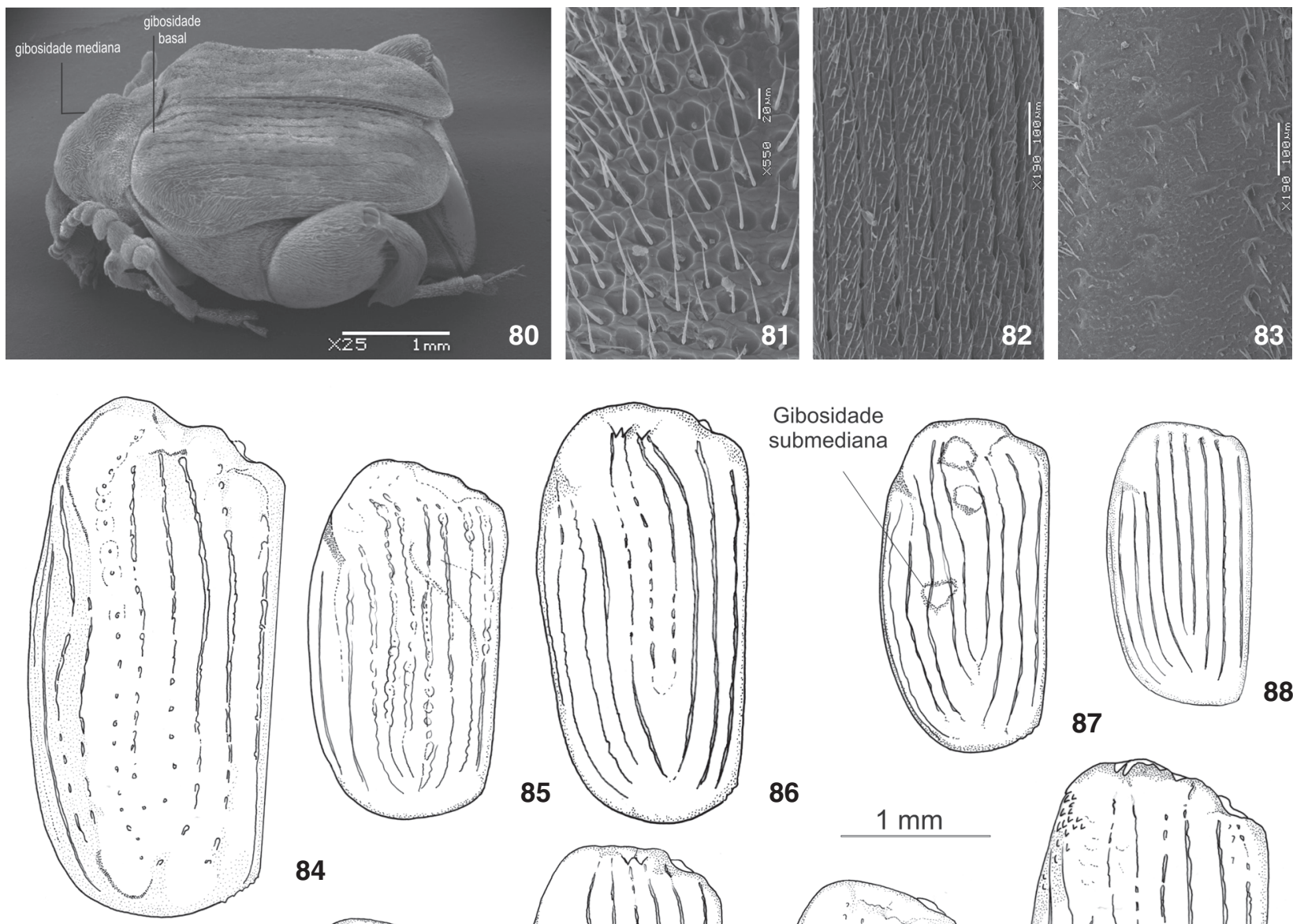

88

84

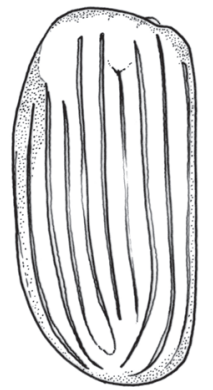

89

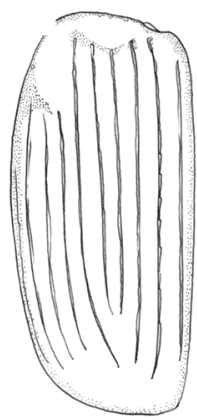

90

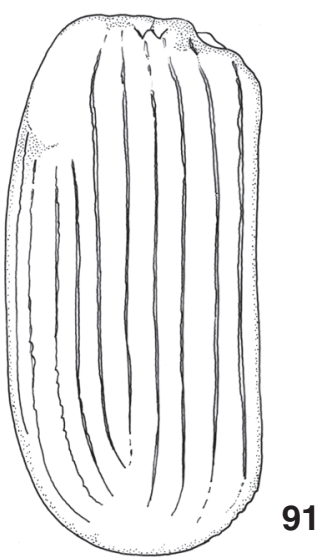

86

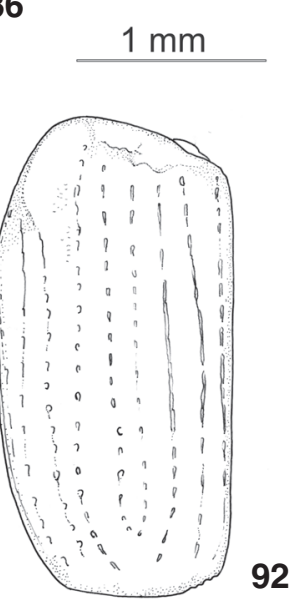

\section{7}

Figuras 80-93. Detalhes do pronoto e estrias do élitro. (80-81) Pronoto: (80) Gibbobruchus speculifer; (81) Meibomeus surrubresus, detalhe do disco. (82-83) Estrias do élitro: (82) M. surrubresus; (83) Pygiopachymerus lineola. (84-93) Élitro: (84) Caryedes brasiliensis; (85) C. godmani; (86) Ctenocolum tuberculatum; (87) Gibbobruchus cavillator; (88) Meibomeus petrolinae; (89) M. musculus; (90) M. surrubresus; (91) Merobruchus julianus; (92) Penthobruchus germaini; (93) Pygiopachymerus lineola.

e 91), diferindo de Caryedes, Ctenocolum, Gibbobruchus, Meibomeus apicicornis, M. funebris, M. musculus, M. surrubresus, Penthobruchus e Pygiopachymerus (Figs 84-87, 90, 92 e 93). As estrias 1-7 são retas na base (Figs 88-93) em G. speculifer, Meibomeus, Merobruchus, Penthobruchus e Pygiopachymerus, enquanto em Caryedes, Ctenocolum e usualmente em Gibbobruchus as 3-6 são encurvadas (Figs
84-87), sendo mais acentuadas em Ctenocolum (Fig. 86). Em Merobruchus há dentes na base das estrias 3 e 4 ou 3-6 (Fig. 91); em Ctenocolum ocorrem sobre forte gibosidade nas estrias 3, 4, algumas vezes 5 e 6 (Fig. 86); em Meibomeus surrubresus (Fig. 90) há um dente largo na base das estrias 3-5 e em Meibomeus apicicornis, M. cyanipennis, M. funebris e M. musculus um dente

Revista Brasileira de Zoologia 25 (4): 802-826, December, 2008 
inconspícuo na base da estria 4. Dentes estão ausentes em Caryedes (exceto C. paradisensis), Gibbobruchus (exceto G. mimus), Meibomeus petrolinae (Fig. 88), M. rodneyi, Penthobruchus e Pygiopachymerus.

Em geral os élitros apresentam gibosidade basal pouco elevada em Caryedes e Penthobruchus, e pouco elevada a conspícua em Gibbobruchus (Fig. 80) e Ctenocolum; Meibomeus e Pygiopachymerus não apresentam gibosidade (exceto Meibomeus ptinoides (Sharp, 1885)). Usualmente em Merobruchus a gibosidade é pouco elevada. Além da gibosidade basal, algumas espécies de Gibbobruchus apresentam gibosidades submediana e apical (WhiteHEAD \& KingSOLVER 1975); em G. cavillator e G. scurra há uma gibosidade submediana (Fig. 87).

Gibosidades nos élitros ocorrem também em Horridobruchus Borowiec, 1984, Meganeltumius e Neltumius (Borowiec 1987, Romero \& JoHnSon 2003a, b).

Metepimero alongado, estreito; metepisterno subretangular, sem sulco parasutural. Metasterno subretangular, projetado próximo às coxas médias em Caryedes (exceto C. godmani) e Pygiopachymerus, e com tegumento homogeneamente micropontuado (Fig. 102), exceto em Caryedes brasiliensis, Ctenocolum tuberculatum e Penthobruchus (Figs 101, 103 e 104) que apresentam fóveas na região lateral. Na região mediana, há uma emarginação mais acentuada em Ctenocolum tuberculatum e Penthobruchus (Figs 103 e 104). Sulco do metasterno curto, exceto em Caryedes brasiliensis que ultrapassa a metade do metasterno (Fig. 101).

Veias das asas com esclerotinização variável; região apical e vanal suavemente esclerotinizadas; Costal (C), Radial (R), Setor radial (RS), Mediana (M), $M_{1+2}$ e $M_{3}$ mais esclerotinizadas. Costal (C) e Subcostal (Sc) em geral fusionadas, exceto em Caryedes brasiliensis (Fig. 108). $\mathrm{M}_{1+2}$, $\mathrm{M}$ e $\mathrm{m}-\mathrm{m}$ formando um arco na região mediana (Figs 108-116). Célula radial quase sempre presente (Fig. 110). Setor radial (RS) subparalela a $R$, na maioria das vezes, formando uma célula mais ampla em Caryedes brasiliensis, Meibomeus surrubresus, M. musculus, Merobruchus paquetae e Penthobruchus (Figs $108,111,112,114$ e 115) e reduzida em Ctenocolum tuberculatum, Pygiopachymerus (Figs 109 e 116). Comprimento de $\mathrm{M}_{1+2}$ variável, geralmente maior ou igual a $1 / 3$ do comprimento de $\mathrm{M}$ e menor em Caryedes cavatus, Ctenocolum tuberculatum, Merobruchus julianus e M. paquetae (Figs 109, 113 e 114). Em geral $M_{1}$ apresenta-se vestigial, exceto em Caryedes brasiliensis e Merobruchus julianus (Figs 108 e 113). Presença de Cu1a em Meibomeus funebris, M. surrubresus, Merobruchus paquetae, M. julianus, M. columbinus, Caryedes, Gibbobruchus, Penthobruchus e Pygiopachymerus (Figs 108, 110, 111 e 113-116), enquanto em Ctenocolum, Meibomeus apicicornis, M. cyanipennis, M. musculus, M. rodneyi, Merobruchus boucheri e M. santarosae esta veia está ausente (Figs 109 e 112). Veia transversa (cv) conectando Cu1a a PCu (Figs 108, 110 e 114116) formando um " $\mathrm{h}$ " em Caryedes, Gibbobruchus, Merobruchus columbinus e Merobruchus paquetae, Penthobruchus e Pygiopachymerus. Kingsolver (2004) comentou que há uma tendência à formação do " $h$ " nos grupos mais derivados de Bruchinae.
Em geral há uma tendência de redução do número de veias em Bruchini, e, de um aumento em Rhaebini e Pachymerini (Kingsolver \& Pfaffenberger 1980, Singh 1981a, Borowiec 1987, JoHnson et al. 2004).

A venação da asa em Bruchinae varia principalmente na região vanal. Nos gêneros estudados foram registradas as seguintes modificações: Cu1a ausente (Fig. 109) ou presente (Fig. 114), Cu1a simples e conectada ou não à PCu (Figs 113 e 116). Caryedes, Gibbobruchus, Penthobruchus e Pygiopachymerus apresentam região vanal semelhante (Cu1a simples e conectada à PCu) (Figs 108, 110, 115 e 116), enquanto em Ctenocolum, freqüentemente em Meibomeus e parte de Merobruchus não há veia Cu1a (Figs 109 e 112). SINGH (1981a) considerou caracteres de venação suficientes para a determinação de nove gêneros em uma chave.

Mesepimero estreito próximo a cavidade coxal (Fig. 94), porém esta condição é pouco visível ventralmente em Meibomeus e Merobruchus julianus, devido às margens laterais do mesepisterno encobrirem parte do mesepimero que é muito estreito próximo às coxas (Figs 95 e 96). Mesosterno usualmente micropontuado, com fóveas esparsas em Merobruchus julianus e Penthobruchus (Figs 96 e 97); processo mesosternal geralmente largo, mais alongado em Meibomeus petrolinae (Fig. 95), com ápice arredondado (Figs 95 e 96), sinuoso em Caryedes brasiliensis (Fig. 94) e truncado em Penthobruchus (Fig. 97).

Proendosternito com braços afilados, retos, levemente mais dilatados no ápice (Figs 78 e 79), exceto em Caryedes brasiliensis em que os braços são sinuosos e o ápice não é dilatado (Fig. 77). Mesendosternito com braços afilados, longos, encurvados e divergentes (Fig. 99); em Caryedes brasiliensis (Fig. 98) e Merobruchus julianus (Fig. 100) os braços formam ângulo obtuso. Metendosternito em forma de "Y", variando na divergência entre os braços (Figs 105-107). Em Penthobruchus o pedúnculo é largo próximo à bifurcação dos braços que são amplamente divergentes e muito afilados no ápice (Fig. 107); em Caryedes (exceto C. brasiliensis), Ctenocolum, Gibbobruchus, Meibomeus, Merobruchus e Pygiopachymerus (Fig. 106) o pedúnculo não é tão largo e os braços são moderadamente divergentes e não afilados no ápice; em Caryedes brasiliensis a base do pedúnculo é mais larga que nas demais espécies (Fig. 105). As seguintes espécies tiveram os metendosternitos ilustrados com padrão semelhante aos dos gêneros estudados, em forma de "Y", Acanthoscelides obtectus (Bruchini) (Daviault 1928), Caryobruchus rubidus (Pachymerini) (CRowson 1944), Rhaebus gleberi Fischer (Rhaebini) (CRowson 1955), Pseudopachymerina spinipes e Penthobruchus germaini (Bruchini) (TERÁn 1962) e Meibomeus cyanipennis (Bruchini) (Ribeiro-Costa \& Silva 2003).

Perna anterior e média sem variações. Coxa posterior com comprimento quase igual à maior largura do fêmur; micropontuação distribuída homogeneamente, quase lisa em Caryedes brasiliensis e Pygiopachymerus. Fêmur posterior mais estreito na base e ápice, com comprimento de 2,0 a 2,5 vezes a sua largura e menos frequentemente 3,0 vezes (Figs 117-129), com tegu- 

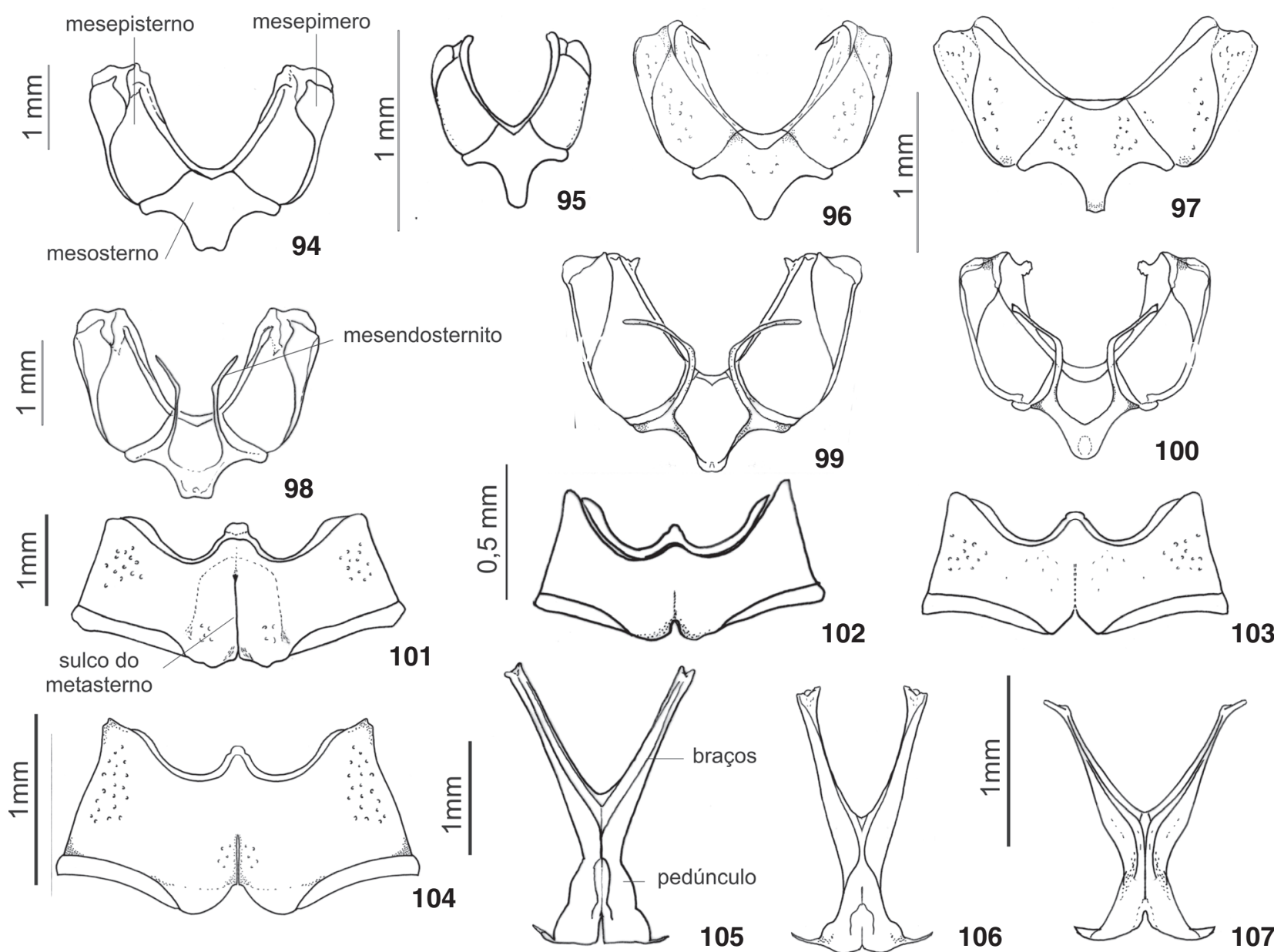

Figuras 94-107. Mesotórax e metatórax. (94-97) Mesotórax, vista ventral: (94) Caryedes brasiliensis; (95) Meibomeus surrubresus; (96) Merobruchus julianus; (97) Penthobruchus germaini. (98-100) Mesotórax, vista interna: (98) C. brasiliensis; (99) C. cavatus; (100) Merobruchus julianus. (101-104) Metatórax, vista ventral: (101) C. brasiliensis; (102) Meibomeus petrolinae; (103) Ctenocolum tuberculatum; (104) P. germaini. (105-107) Metendosternito: (105) C. brasiliensis; (106) C. cavatus; (107) P. germaini.

mento em geral liso, exceto em Penthobruchus e Pygiopachymerus (Figs 128 e 129), que apresentam fóveas esparsas na metade distal; margem externa sem carenas ou dentes em Merobruchus e Meibomeus (Figs 123-127) e com dentes em Caryedes (exceto $C$. paradisensis), Ctenocolum, Gibbobruchus, Penthobruchus e Pygiopachymerus (Figs 117, 118, 120-122, 128 e 129). Em Caryedes os dentes são em geral reduzidos e mais freqüentes na região apical (Kingsolver \& Whitehead 1974b). Whitehead \& Kingsolver (1975) utilizaram esse caráter para indicar proximidade entre os grupos Caryedes e Gibbobruchus (Fig. 1).

Meibomeus e Caryedes compartilham o sulco ventral do fêmur posterior raso enquanto nos demais gêneros é profundo. Esses gêneros também são os únicos com pré-pécten (Figs 117-119 e 123-125), porém este varia no número de dentes; Meibomeus rodneyi tem um único dente semelhante aos do pécten (Fig. 125) enquanto em Caryedes geralmente há mais dentes que nas espécies de Meibomeus. O pécten é bastante variado com relação ao desenvolvimento, número e espaçamento entre os dentes, em geral com mais de três dentes, o primeiro maior que os restantes. Ctenocolum (exceto C. colburni e C. podagricus) apresenta pécten fortemente projetado com cerca de 8-16 dentes em fileira (Fig. 121); em Ctenocolum colburni e C. podagricus os dentes são reduzidos a 6 , sendo o primeiro distanciado dos demais (Fig. 120). Caryedes brasiliensis, C. helvinus, C. longifrons, C. paradisensis e apresentam pécten projetado e com dentes variando em espaçamento (Figs 117, 119, 123 e 125). O pécten em Meibomeus é muito pouco projetado. Em $M$. musculus tem aspecto distinto das demais espécies do gênero, variando de 3-4 dentes, o primeiro separado dos demais por espaço (Fig. 124; nas demais espécies de Meibomeus o número de dentes varia de 4-6 (Figs 123 e 125). Merobruchus possui pécten moderadamente projetado, em geral com 3-6 dentes 

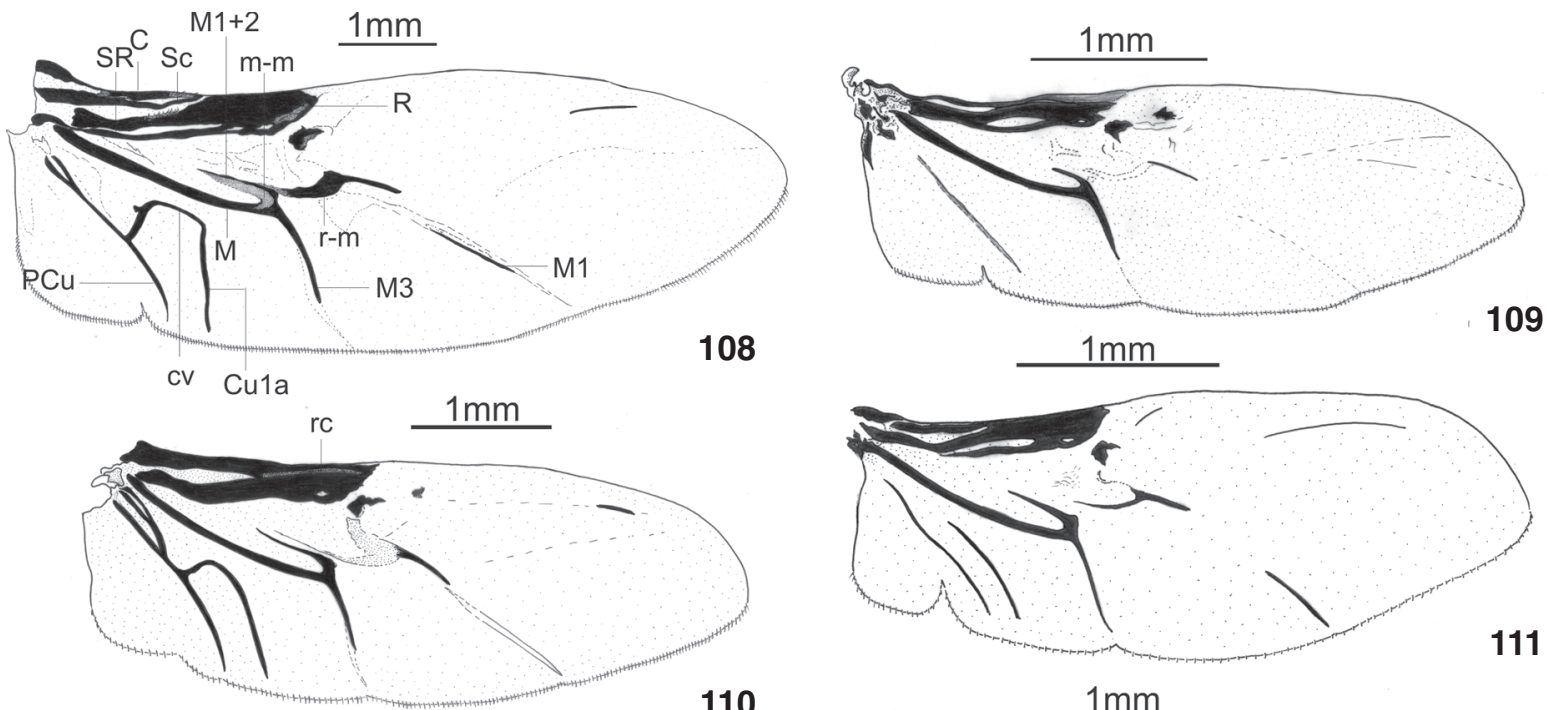

110
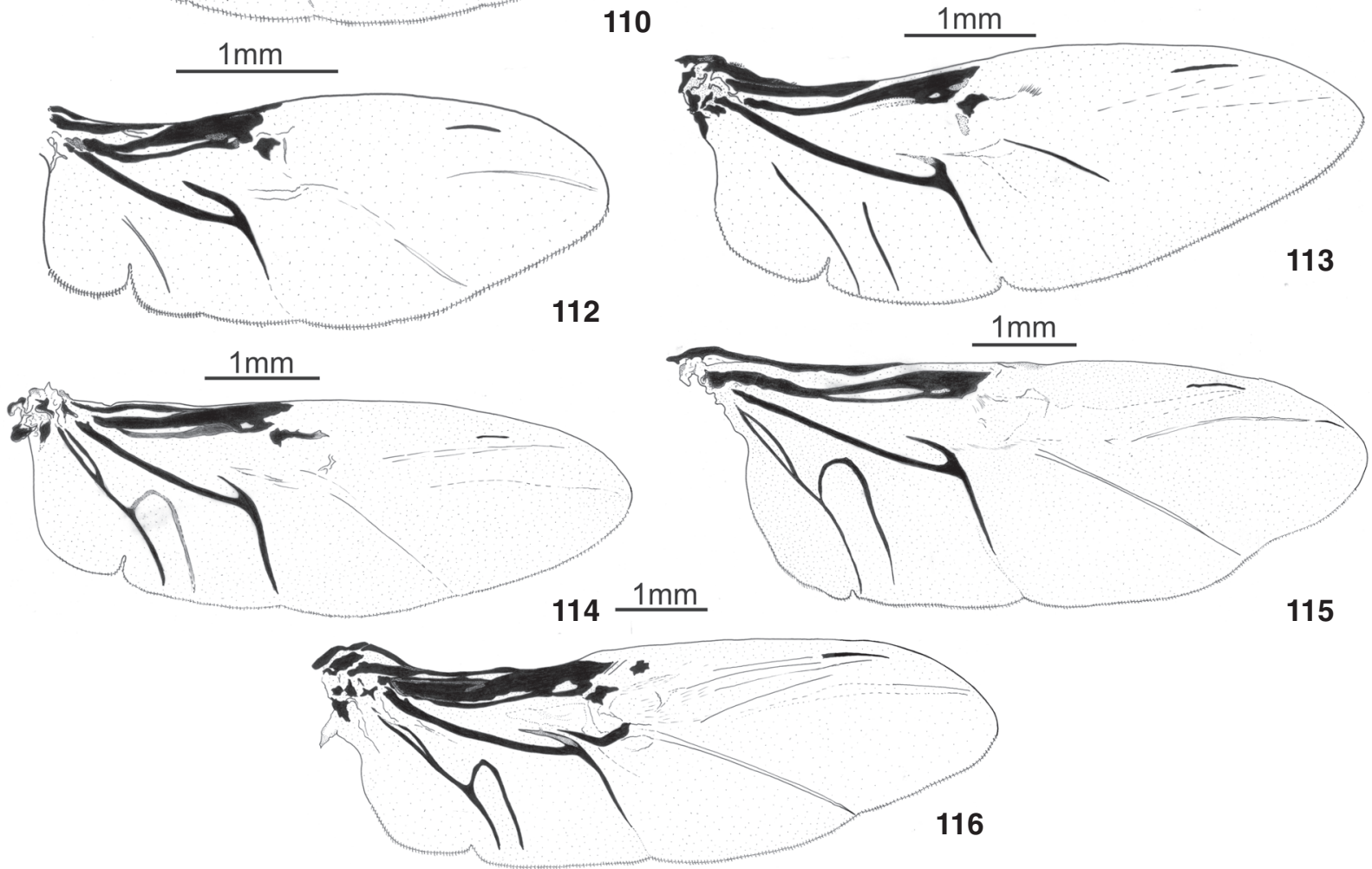

Figuras 108-116. Asa: (108) Caryedes brasiliensis; (109) Ctenocolum tuberculatum; (110) Gibbobruchus speculifer; (111) Meibomeus surrubresus; (112) M. musculus; (113) Merobruchus julianus; (114) M. paquetae; (115) Penthobruchus germaini; (116) Pygiopachymerus lineola. (C) Veia costal, (cv) veia transversa cubital, (Cu1a) veia cubital, (M) veia mediana, (M1) mediana 1, (M1+2) mediana 1+2, (M3) mediana 3, (m-m) veia mediana transversa, (Pcu) veia pós-cubital, $(\mathrm{R})$ veia radial, $(\mathrm{rc})$ célula radial, $(\mathrm{r}-\mathrm{m})$ veia transversa radio-mediana, (Sc) subcostal, (SR) setor radial.

variando em espaçamento. Merobruchus e Meibomeus apresentam algumas espécies com número reduzido de dentes (3-5), quando comparado com os demais gêneros estudados. Em
Caryedes cavatus, C. godmani, C. stenocephalus, C. x-liturus, Gibbobruchus, Penthobruchus e Pygiopachymerus, o pécten é moderadamente projetado, sendo os três últimos com dentes lar- 

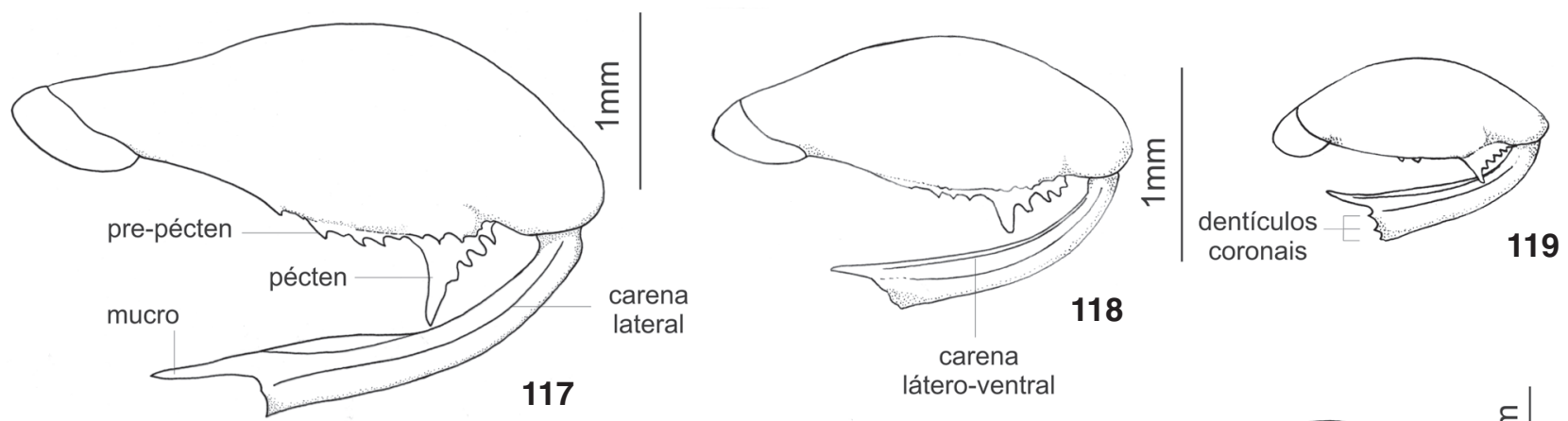

119

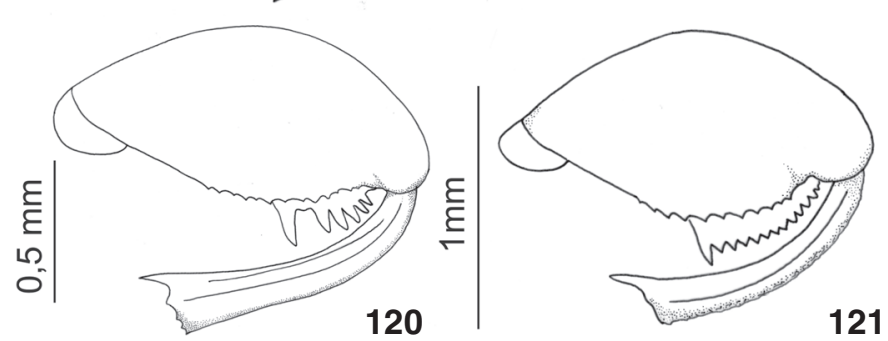

látero-ventral

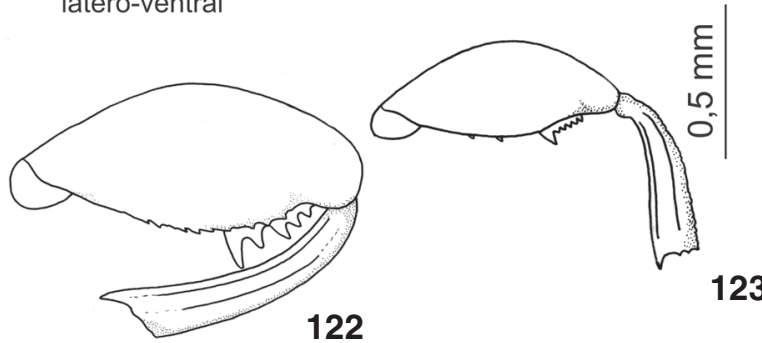

121
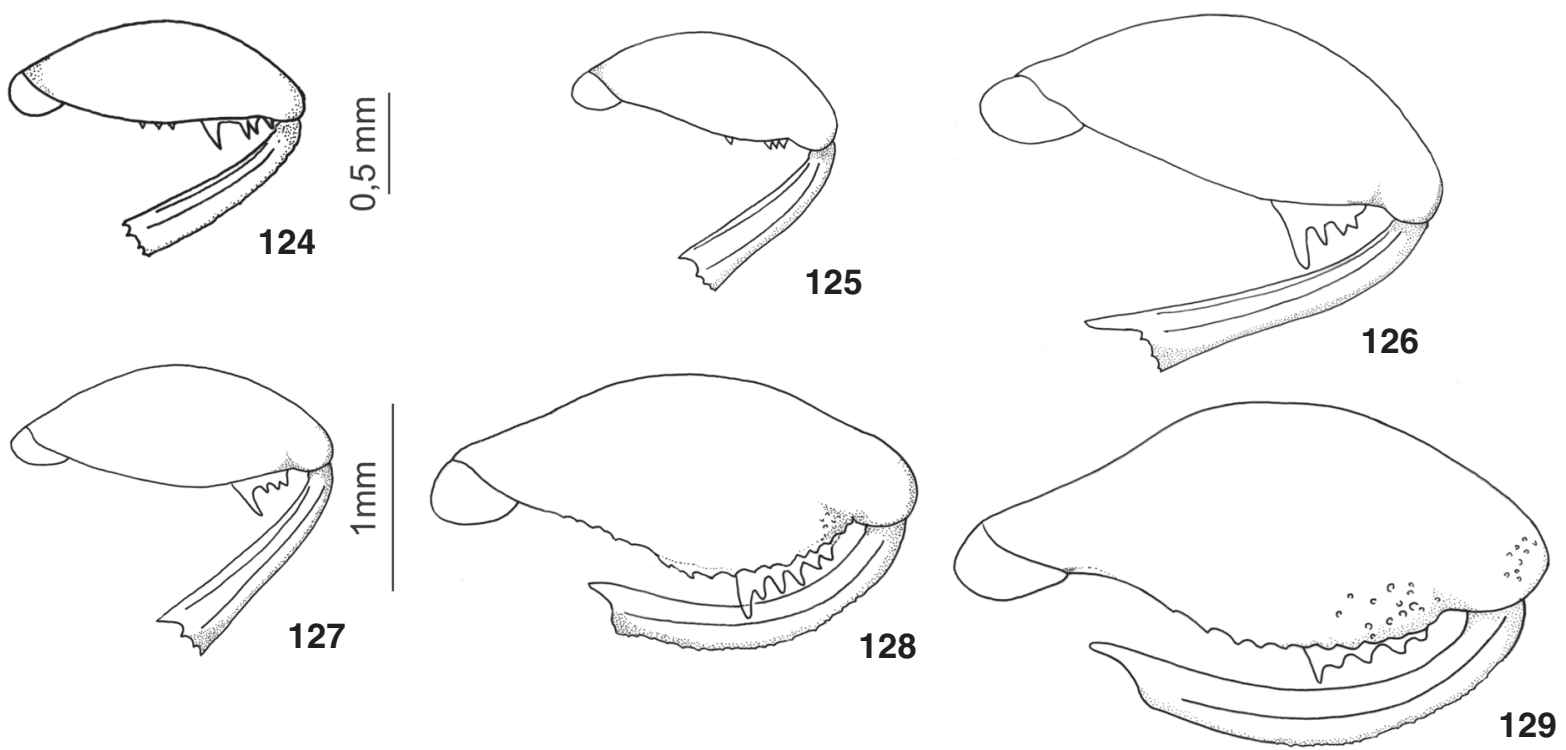

Figuras 117-129. Perna posterior, exceto coxa e tarso: (117) Caryedes brasiliensis; (118) C. cavatus; (119) C. paradisensis; (120) Ctenocolum podagricus; (121) C. tuberculatum; (122) Gibbobruchus speculifer; (123) Meibomeus cyanipennis; (124) M. musculus; (125) M. rodneyi; (126) Merobruchus columbinus; (127) M. julianus; (128) Penthobruchus germaini; (129) Pygiopachymerus lineola.

gos, irregularmente espaçados (Figs 118, 122, 128 e 129).

A curvatura da tíbia posterior depende do grau de desenvolvimento do pécten (Romero \& Johnson 2002). Em Meibomeus, Merobruchus e Caryedes a tíbia é quase reta, quando muito suavemente encurvada (Figs 117-120 e 123-127), em Ctenocolum e Gibbobruchus em geral encurvada (Figs 121 e 122) e é fortemente encurvada em Penthobruchus Pygiopachymerus (Figs 128 e 129), como ocorre nos Pachymerini (NiLsson \& Johnson 1993). Ctenocolum (exceto C. podagricus), Penthobruchus e Pygiopa- chymerus não apresentam carena látero-ventral na tíbia posterior (Figs 121, 128 e 129), diferem também pela carena externa microserreada, sendo mais evidente nos dois últimos gêneros. Essa última condição foi também observada em Meibomeus cyanipennis, M. funebris e M. musculus. Em Acanthoscelidina o número de carenas na tíbia posterior é variável, e a ausência da carena látero-ventral é verificada em Bruchidius, Conicobruchus Decelle, 1951, Decellebruchus, Salviabruchus Decelle, 1982, Sulcobruchus Chujo, 1937 e Specularius, em algumas espécies de 

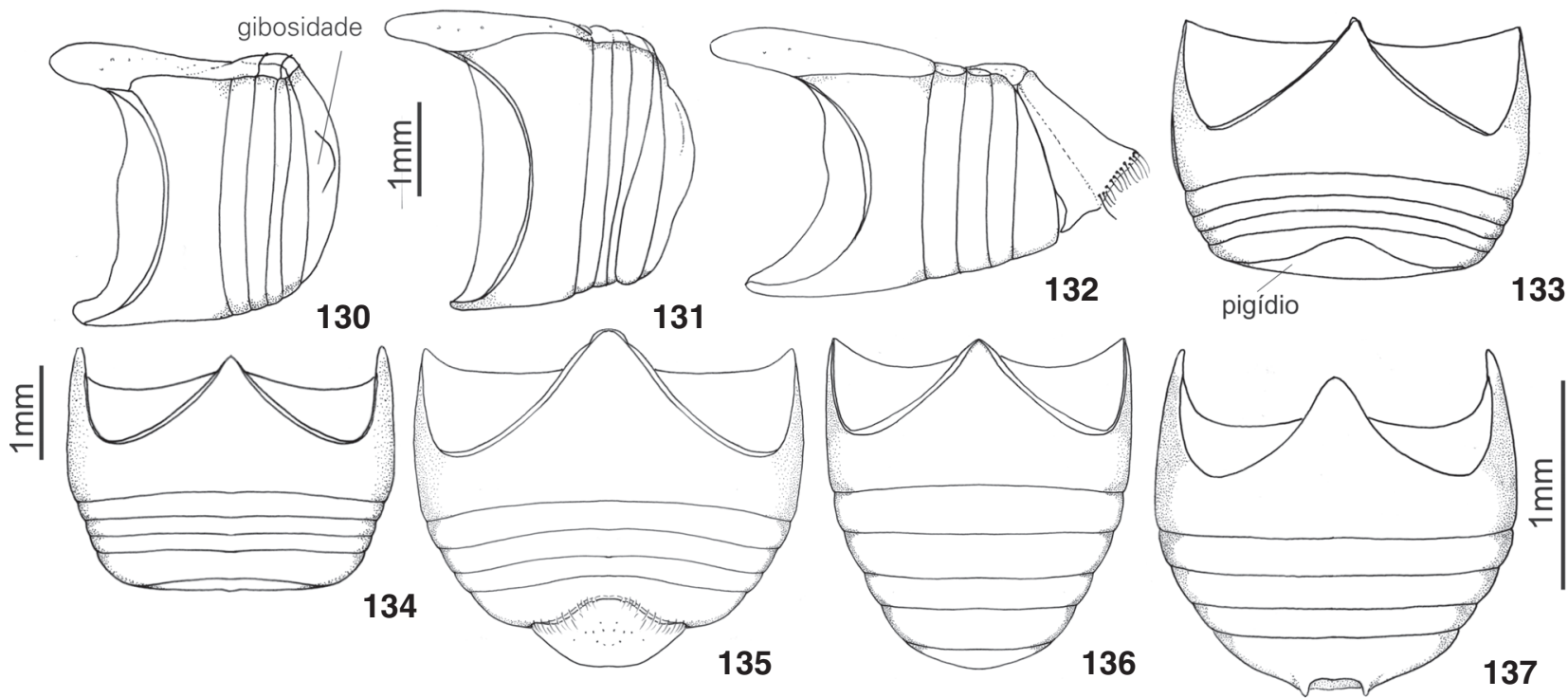

Figuras 130-137. Abdome. (130-132) Vista lateral: (130) Caryedes brasiliensis, macho; (131) C. brasiliensis, fêmea; (132) C. cavatus, fêmea. (133-137) Vista ventral: (133) C. brasiliensis, macho; (134) C. brasiliensis, fêmea; (135) C. cavatus, fêmea; (136) Gibbobruchus speculifer, macho; (137) Merobruchus julianus, fêmea.

Sennius e Acanthoscelides (Borowiec 1987, Johnson 1990, SiLva et. al. 2003). Em Pachymerini há tendência em um maior número de carenas, principalmente em Pachymerus Thunberg, 1805 (NiLsson \& Johnson 1993), enquanto em Amblycerini não há carenas.

O comprimento do mucro é um caráter variável dentro dos gêneros (Figs 118-130). Em Ctenocolum, Gibbobruchus, Merobruchus, Penthobruchus e Pygiopachymerus é curto, ou maior que a metade da largura do ápice da tíbia (Figs 118, 120-122, 125 e 129). Em Caryedes pode apresentar-se igual ou muito maior que a largura do ápice da tíbia (Figs 117 e 119). Em Meibomeus é muito curto, obsoleto. Os dentículos coronais são agudos e desenvolvidos em Meibomeus e Merobruchus, e nas espécies Ctenocolum colburni, Ctenocolum podagricus, Gibbobruchus mimus, Caryedes helvinus, Caryedes paradisensis, Caryedes stenocephalus e Caryedes x-liturus (Figs 119, 120 e 123-127).

A maioria das espécies não apresenta carena lateral no primeiro tarsômero posterior, que é evidente em Caryedes cavatus, C. paradisensis, Gibbobruchus scurra, Merobruchus julianus e M. paquetae.

Abdome. Pigídio subretangular com margens laterais encurvadas e ápice arredondado (Figs. 25-29), ou triangular, com ápice agudo em Caryedes godmani (Fig. 4). Em geral diferenças entre machos e fêmeas no pigídio consistem na coloração e distribuição da pilosidade, como em Ctenocolum tuberculatum (Figs 25-26), Gibbobruchus scurra (Figs 28 e 29) e Pygiopachymerus (Figs 30 e 31). Apenas Meibomeus não apresenta dimorfismo sexual no pigídio. Em Caryedes brasiliensis os machos apresentam gibosidades na região mediana e lateral do pigídio (Figs 21 e 130), e as fêmeas um sulco na região mediana em forma de "V" (Fig. 22). Apenas em Caryedes cavatus o pigídio da fêmea, em vista lateral, forma ângulo obtuso com o quinto urosternito e apresenta cerdas no ápice (Figs 24 e 132). Em Penthobruchus as fêmeas possuem modificações no tegumento semelhantes a duas listras, encurvadas e divergentes.

Quinto urosternito com ápice de moderado a fortemente emarginado nos machos (Fig. 133), enquanto nas fêmeas essa emaginação não é acentuada (Fig. 134). Diferenças nesse padrão são encontradas no ápice emarginado do quinto urosternito da fêmea de Caryedes cavatus (Figs 132 e 135) e no quinto urosternito não emarginado do macho de Gibbobruchus speculifer (Fig. 136). Em Merobruchus, há uma suave ou forte chanfradura no ápice do quinto urosternito visível, sendo mais evidente nas fêmeas (Fig. 137), caráter comum na maioria das espécies desse gênero (KINGsolver 1988).

Genitália do macho. Caryedes (exceto C. x-liturus), Meibomeus, Ctenocolum podagricus e Gibbobruchus speculifer distinguem-se pelo lobo médio extremamente alongado, com comprimento cerca de seis vezes a maior largura na base da valva ventral (Figs 138, 139 e 143-145). O extremo alongamento da genitália do macho e suave emarginação entre os lobos laterais do tégmen em Caryedes e Meibomeus indicam maior afinidade entre esses gêneros segundo Kingsolver \& WhiteheAd (1974a, b, 1976).

A região basal do lobo médio é muito variável, quase sempre larga, sendo mais estreita em Caryedes brasiliensis, C. helvinus e C. godmani (Fig. 138).

Na maioria dos gêneros o lobo médio apresenta-se sem constrição ou fratura próximo ao ápice. Em Caryedes brasiliensis (Fig. 138) ocorre uma constrição e em Meibomeus funebris e $M$. 


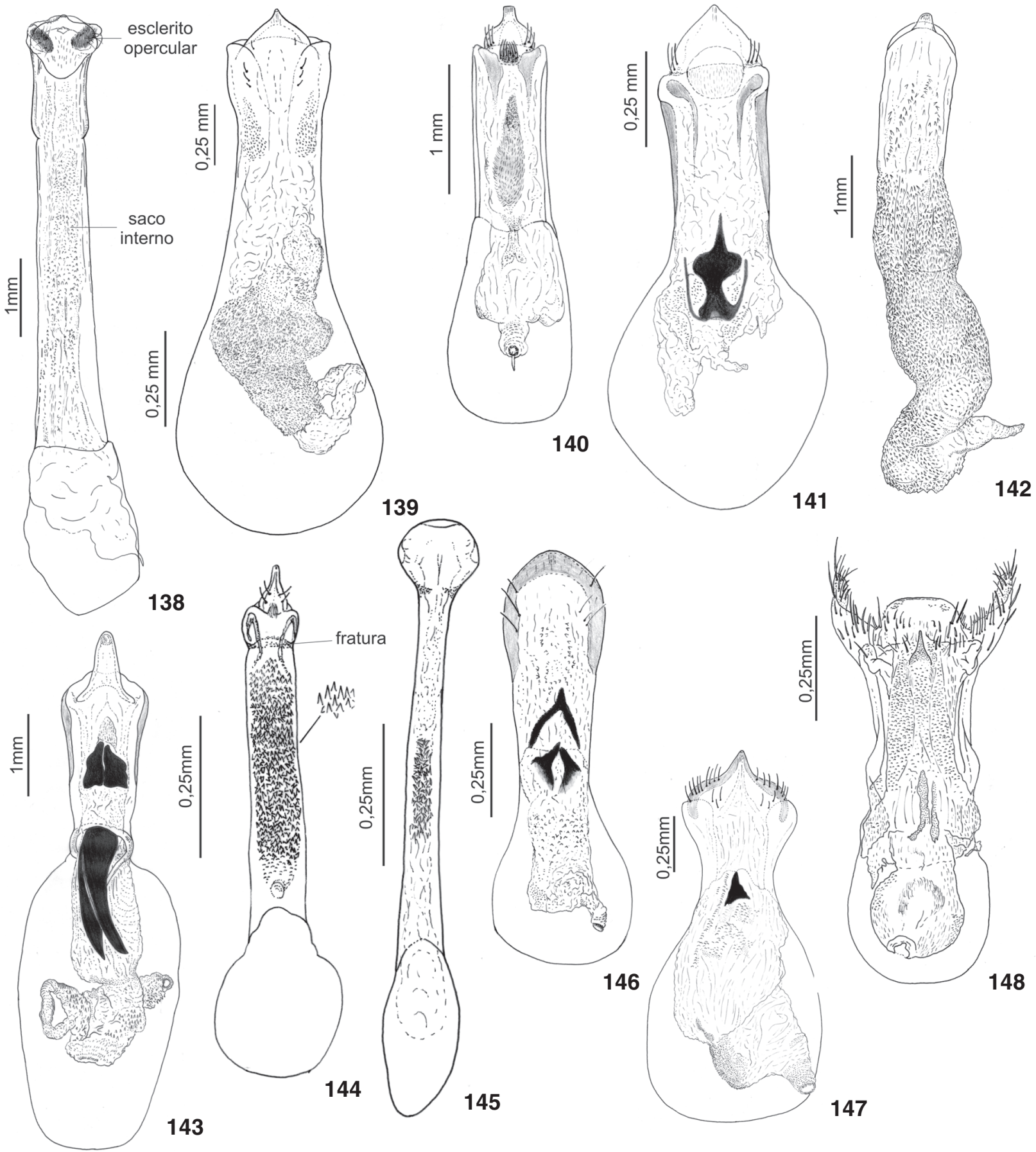

Figuras 138-148. Lobo médio da genitália do macho: (138) Caryedes brasiliensis; (139) C. x-liturus; (140) Ctenocolum podagricus; (141) C. janzeni; (142) Gibbobruchus mimus; (143) G. speculifer; (144) Meibomeus funebris; (145); M. rodneyi (146); Merobruchus paquetae; (147) Penthobruchus germaini; (148) Pygiopachymerus lineola.

cyanipennis (Fig. 144) há uma fratura contínua. Esta condição é encontrada em espécies de Caryedes e em Meibomeus (KINGSOLver \& Whitehead 1974b, 1976, Silva \& Ribeiro-Costa 2001). Na re- gião apical, o lobo médio geralmente é suavemente encurvado, exceto por Meibomeus rodneyi em que a curvatura é muito acentuada. 


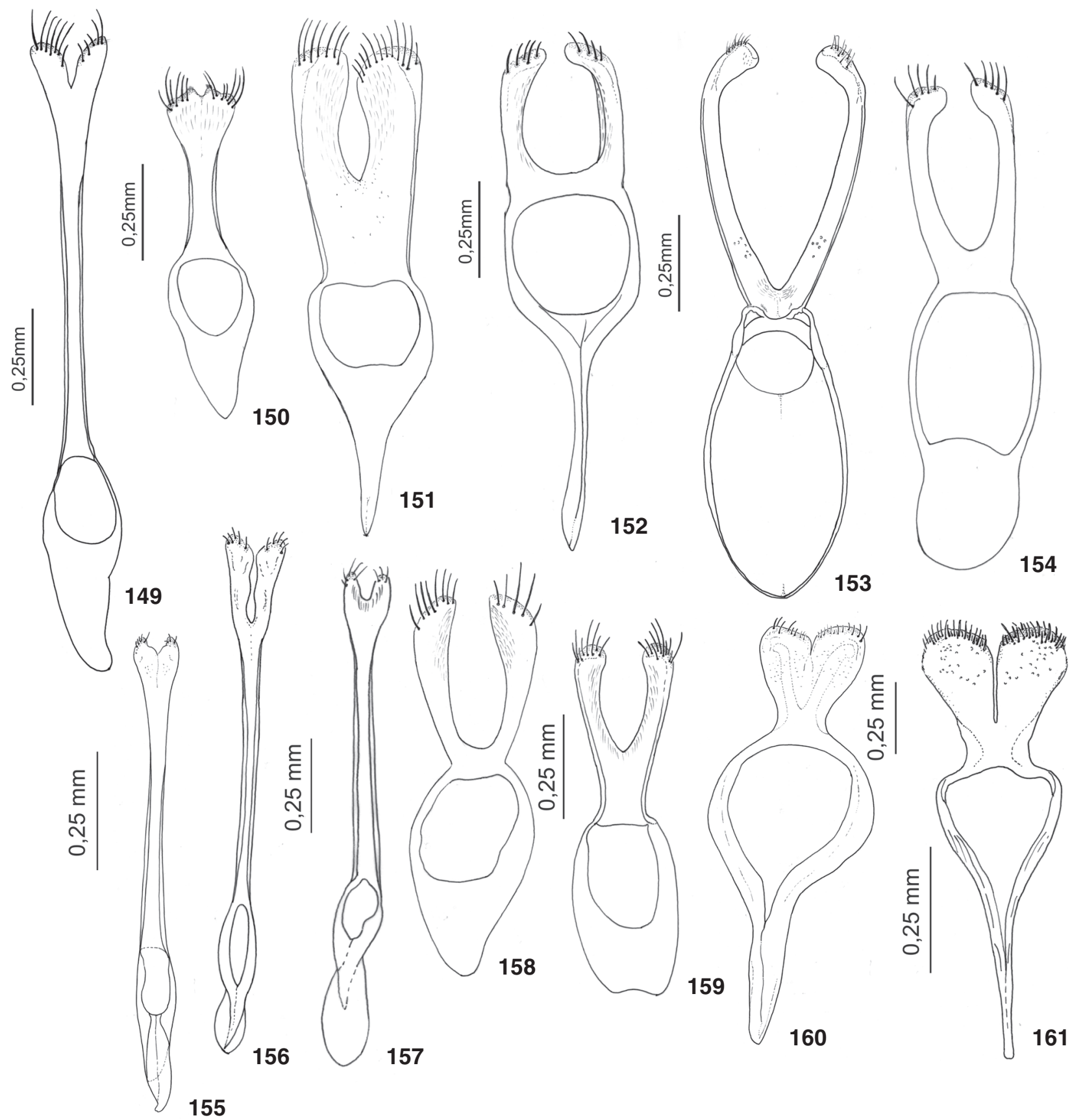

Figuras 149-161. Tégmen da genitália do macho: (149) Caryedes helvinus; (150) C. paradisensis; (151) Ctenocolum janzeni; (152) C. tuberculatum; (153) Gibbobruchus speculifer; (154) G. cavillator; (155) Meibomeus musculus; (156) M. rodneyi; (157) M. surrubresus; (158) Merobruchus boucheri; (159) M. julianus; (160) Penthobruchus germaini; (161) Pygiopachymerus lineola.

Expansões látero-apicais no lobo médio só ocorrem em Pygiopachymerus (Fig. 148), uma provável apomorfia para esse gênero. Valva dorsal em geral curta, pouco desenvolvida e a ventral subtriangular. A ventral de Merobruchus é arredondada, curta, com base larga (Fig. 146), a de Pygiopachymerus é subtruncada no ápice (Fig. 148) e as de Caryedes longifrons, Ctenocolum colburni e C. podagricus são subtriangulares com ápice truncado (Fig. 140), já em Meibomeus rodneyi tem forma singu- 


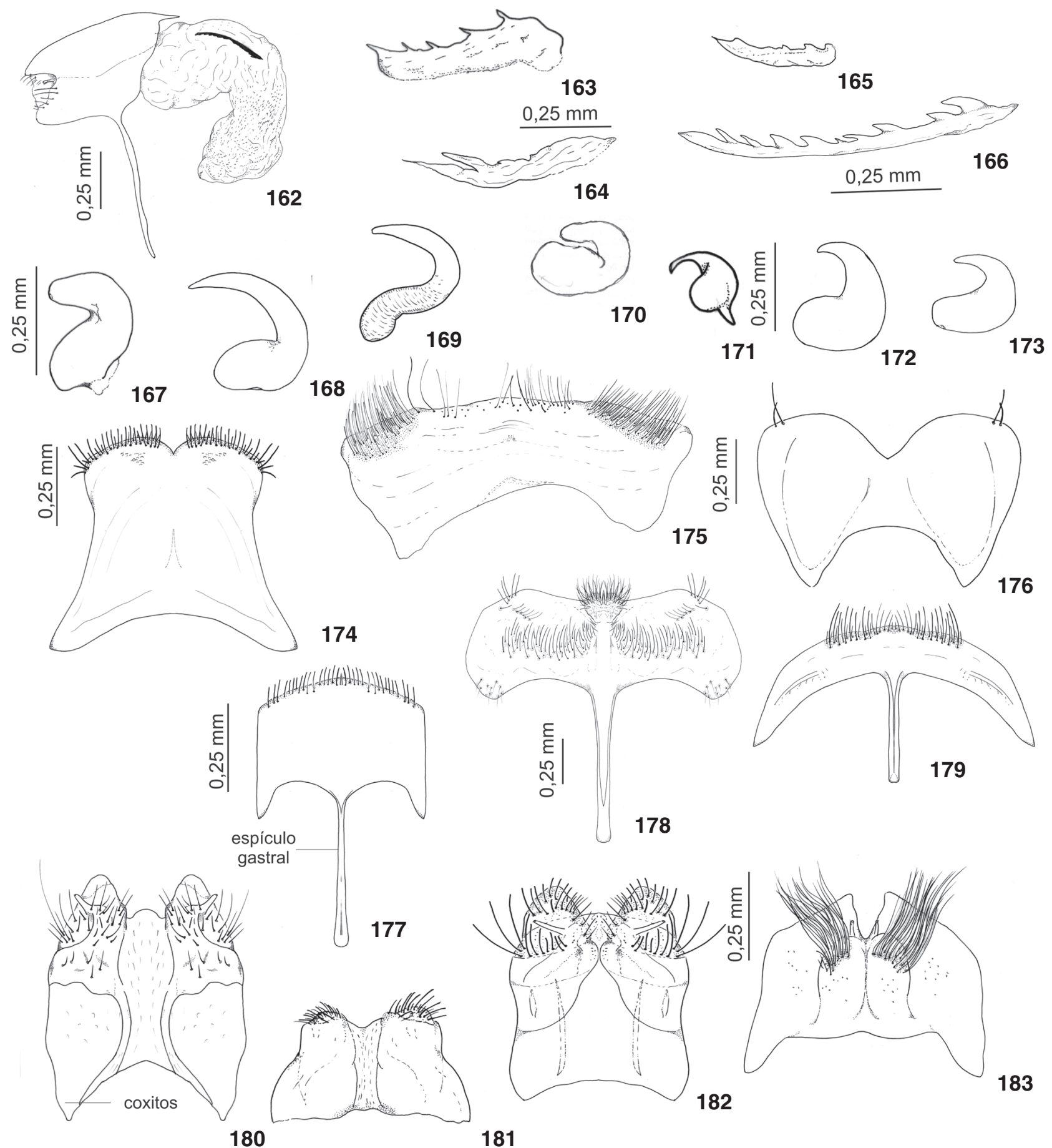

Figuras 162-183. Genitália da fêmea: (162) Caryedes x-liturus, vista lateral. (163-166) Esclerito da bursa: (163) C. brasiliensis; (164) C. helvinus; (165) Merobruchus santarosae; (166) Meibomeus funebris. Espermateca (167-173): (167) Caryedes brasiliensis; (168) C. cavatus; (169) Gibbobruchus guanacaste; (170) G. speculifer; (171) Meibomeus cyanipennis; (172) Penthobruchus germaini; (173) Pygiopachymerus lineola. (174-176) Oitavo urotergito: (174) Caryedes brasiliensis; (175) C. cavatus; (176) Gibbobruchus speculifer. (177-179) Oitavo urosternito: (177) Caryedes brasiliensis; (178) C. cavatus; (179) Gibbobruchus speculifer. (180-181) Ovipositor: (180) Caryedes brasiliensis; (181) Gibbobruchus speculifer; (182) Pygiopachymerus lineola; (183) Caryedes cavatus.

Revista Brasileira de Zoologia 25 (4): 802-826, December, 2008 
lar (Fig. 145). Dos gêneros estudados, Meibomeus apresenta espécies com valva ventral de várias formas (Kingsolver \& WhiteHeAd 1976, Romero \& JoHNSON 2002).

Saco interno do lobo médio varia com relação a presença de escleritos e dentículos. Escleritos operculares variáveis quanto a forma e a esclerotinização e provavelmente atuam na abertura das valvas durante a cópula (JoHnson \& Kingsolver 1973). Ocorrem em Ctenocolum (Figs 140 e 141), Caryedes (exceto C. cavatus, C. paradisensis e C. x-liturus Fig. 139) e Meibomeus (exceto M. rodneyi e M. surrubresus) (Figs 138 e 144). No entanto, a ausência de escleritos operculares é a condição mais comum. São característicos de Sennius Bridwell, 1946 (Johnson \& KINGSOlver 1973) e do gênero monotípico Megasennius Whitehead \& Kingsolver, 1975.

Caryedes, Ctenocolum colburni, C. podagricus, Gibbobruchus (exceto G. speculifer), Meibomeus (exceto M. surrubresus) e Pygiopachymerus não apresentam escleritos internos diferentes dos operculares. Escleritos são raros em Meibomeus e Gibbobruchus (Whitehead \& Kingsolver 1975, Kingsolver \& Whitehead 1976, Silva \& Ribeiro-Costa 2001). Formas variadas de escleritos foram observadas em Ctenocolum tuberculatum e C. janzeni (Fig. 141), do grupo tuberculatum e também nas outras duas espécies desse grupo (Kingsolver \& WhiteheAd 1974a).

Região mediana do saco interno de Merobruchus com esclerito em forma de "Y" invertido e um par de escleritos alongados (Fig. 146). Segundo Kingsolver (1988), Merobruchus, exceto M. major, apresenta escleritos no saco interno, sendo freqüente a presença do esclerito em " $Y$ " invertido, distintivo deste gênero. Em Meibomeus apicicornis, M. funebris, M. musculus, Gibbobruchus mimus, G. scurra e G. guanacaste (Figs 142 e 144) há um maior número de dentículos no saco interno diferindo de Ctenocolum, Merobruchus, Penthobruchus e Pygiopachymerus em que não há dentículos.

O tégmen em geral tem lobos laterais com ápice arredondado, fortemente emarginados e com suporte largo (Fig. 154). Caryedes e Meibomeus apresentam tégmen extremamente alongado com emarginação suave entre os lobos laterais (Figs 149 e 155-157). A emarginação é acentuada em Ctenocolum, Gibbobruchus, Merobruchus e Pygiopachymerus (Figs 151-154, 158, 159 e 161) e os lobos são fusionados em Caryedes paradisensis (Fig. 150). Penthobruchus também apresenta emarginação suave (Fig. 160), porém o tégmen não se apresenta tão alongado quanto os de Caryedes e Meibomeus.

O ápice dos lobos laterais é afilado em Gibbobruchus speculifer (Fig. 153), levemente agudo em Meibomeus musculus (Fig. 155), e arrendondado, moderadamente expandido nas demais espécies. Em Penthobruchus e Pygiopachymerus, o ápice dos lobos laterais é fortemente expandido (Figs 160 e 161).

Em geral, há forte emarginação entre os lobos laterais. No caso de Caryedes paradisensis (Fig. 150), Meibomeus matoensis (Pic, 1933), Pachymerini e Megacerini os lobos laterais são fusionados (Nilsson \& Johnson 1993, TerÁn \& Kingsolver 1977, Silva \& Ribeiro-Costa 2001).
Dos gêneros estudados, Ctenocolum, Meibomeus, Penthobruchus e Pygiopachymerus possuem suporte do tégmen estreito com quilha mediana (Figs 151, 152, 155, 156, 160 e 161).

Genitália da fêmea. Em Bruchinae a bursa pode apresentar desde escleritos a dentículos esparsos (TERÁN 1962, Borowiec 1987, NiLsson \& Johnson 1993). A presença de escleritos ocorre em algumas espécies de Pachymerini (NILSSON \& Johnson 1993), e em Amblycerus Thunberg, 1815 (Ribeiro-Costa \& Silva 2003). Também foram ilustrados por Borowiec (1987) variados escleritos em Bruchidius e Callosobruchus.

A bursa não apresenta escleritos nos gêneros estudados, com exceção de algumas espécies de Caryedes, Meibomeus e Merobruchus (Fig. 162). Em C. brasiliensis, C. helvinus e Merobruchus santarosae o esclerito é curto (Figs 163-165) e em Meibomeus funebris e Caryedes x-liturus o esclerito é longo e serreado (Fig. 166).

A espermateca tem forma de " $\mathrm{C}$ " invertido em todos os gêneros, com variações na curvatura e na largura da base e do ápice (Figs 167-173). Apenas em Caryedes cavatus e Gibbobruchus guanacaste apresenta-se mais afilada (Figs 168 e 169). A base geralmente é larga exceto Gibbobruchus guanacaste e em Meibomeus cyanipennis há uma pequena projeção (Fig. 171). Ápice extremamente encurvado ocorre em Gibbobruchus speculifer (Fig. 170).

O oitavo urotergito em geral é largo, subretangular, e o ápice apresenta cerdas em diferentes áreas (Figs 174, 175, 176). A margem anterior em geral é bilobada (Figs 174 e 176). Em Caryedes cavatus, Meibomeus cyanipennis e Pygiopachymerus o ápice é inteiro. Em Caryedes cavatus cada lado do oitavo urotergito, há uma área com cerdas adensadas próximas ao ápice (Fig. 175). Oitavo urosternito retangular, margem anterior subtruncada, com cerdas distribuídas na margem (Fig. 177). Margens laterais encurvadas ocorrem em Caryedes cavatus e Gibbobruchus speculifer (Figs 178 e 179). O espículo gastral é afilado e tão longo quanto a largura do ápice do urosternito, sendo mais curto em Gibbobruchus speculifer (Fig. 179). O ovipositor é subquadrado, com emarginação entre os coxitos, cerdas no ápice e dois estilos delgados e curtos (Fig. 180). Em Gibbobruchus speculifer o ovipositor é curto, subretangular (Fig. 181), e em Caryedes cavatus as cerdas são muito alongadas (Fig. 183). Em Pygiopachymerus os estilos destacam-se por serem mais longos (Fig. 182).

\section{Chave para os gêneros do grupo Merobruchus}

1. Fêmur posterior sem dentes na margem externa (Figs $126 \mathrm{e}$ 127)

1'. Fêmur posterior com dentes ou dentículos na margem externa (Figs 117, 120, 121 e 128) ................................... 4

2. Cabeça geralmente alongada (Fig. 32). Estrias elitrais encurvadas na base (Figs 3-7, 84 e 85). Mucro igual ou maior que a largura do ápice da tíbia posterior (Figs 117-119) ... Caryedes Hummel

2'. Cabeça curta (Fig. 41). Estrias elitrais retas (Figs 82 e 88-91). Mucro obsoleto, curto ou maior que a metade da largura do ápice da tíbia posterior (Figs 123-127) ........................ 3 
3. Tegumento inteiramente negro; pilosidade no pronoto e élitro rala (exceto M. musculus (Say, 1831)) (Figs 13 e 14). Quarta estria do élitro abreviada ou não na base, com ou sem dente, nunca sobre gibosidade (exceto M. ptinoides) (Figs 88 e 89). Mucro obsoleto (Figs 123-125). Primeiro urosternito com estreita faixa vertical glabra, lateralmente (exceto $\mathrm{M}$. juarez Romero \& Johnson, 2002 e machos de M. jacki Romero \& Johnson, 2002). Genitália do macho: Lobo médio longo e delgado, valva ventral com diversas formas; saco interno raramente com escleritos desenvolvidos (Figs 144 e 145); lobos laterais do tégmen suavemente emarginados (Figs 155157) ................................................. Meibomeus Bridwell

3'. Tegumento com outra coloração; pilosidade no pronoto e élitro densa (Figs 15-17). Estrias do élitro nunca abreviadas, com dentes na base das estrias 3 e 4 ou 3-6 sobre gibosidade pouco elevada a moderada (Fig. 91). Mucro curto ou maior que a metade da largura do ápice da tíbia posterior (Figs 126 e 127). Primeiro urosternito sem áreas glabras lateralmente. Genitália do macho: Lobo médio curto e largo; valva ventral larga, subarredondada no ápice; saco interno freqüentemente com esclerito em forma de " $Y$ " invertido (Fig. 146); lobos laterais do tégmen profundamente emarginados (Figs 158 e 159) ........... Merobruchus Bridwell

4. Gena alongada (Figs 32-34 e 38). Esternos abdominais uniformemente pilosos (exceto Caryedes incrustatus (Gyll. 1833) e Ctenocolum acapulcensis Kingsolver \& Whitehead, 1974)...5

4'. Gena curta (Figs 40-42). Esternos abdominais com amplas áreas glabras - exceto Gibbobruchus speculifer (Gyll., 1833) e G. ornatus Pic, 1931

5. Base das estrias elitrais 3,4 , algumas vezes 5 e 6 com dentes sobre forte gibosidade (Figs 8, 9 e 86). Asa sem veias Cu1a e cv (Fig. 109). Fêmur posterior sem pré-pécten. Pécten com 6-9 dentes espaçados após o primeiro dente, ou com 12-16 dentes projetados em fileira. Mucro curto (Figs 120 e 121). Genitália do macho: Lobo médio em geral pouco alongado (Fig. 141), lobos laterais fortemente emarginados (Figs 151 e 152) Ctenocolum Kingsolver \& Whitehead

5 '. Base das estrias elitrais sobre gibosidade pouco elevada, essas sem dentes, ou com um único dente na quarta estria (Figs 3-7, 84 e 85). Asa com cv conectando Cu1a a PCu (Fig. 108). Fêmur posterior com pré-pécten. Pécten com 3-6 dentes variando em espaçamento. Mucro muito longo (Figs 117119). Genitália do macho: Lobo médio em geral muito alongado e delgado (Fig. 138); lobos laterais do tégmen suavemente emarginados (Fig. 149) ..... Caryedes Hummel

6. Mola das mandíbulas com dentes desenvolvidos (Fig. 58); gálea com cerdas simples e pectinadas (Figs 63 e 64). Gibosidade mediana do pronoto na maioria das vezes conspícua, freqüentemente dividida por sulco médio transverso (Figs 11, 12, 71, 74 e 80). Tíbia posterior encurvada ou reta, sem rugosidade na margem externa (Fig. 122). Pigídio das fêmeas com área glabra ampla e polida na região mediana-apical, também presente nos machos de $G$. speculifer, G. ornatus e G. polycoccus (Fahraeus, 1839) (Figs 27 e 29) Gibbobruchus Pic

6'. Mola das mandíbulas sem dentes desenvolvidos (Figs 60 e 61); gálea apenas com cerdas simples (Fig. 66). Gibosidade mediana do pronoto ausente. Tíbia posterior fortemente encurvada e com rugosidade na margem externa (Figs 128 e 129). Pigídio das fêmeas uniformemente piloso ou quando muito com pequena área central pilosa (Figs 30 e 31) .... 7

7'. Lobo pós-ocular estreito (Fig. 46). Estrias elitrais formadas por pontos isolados e alinhados; sem áreas rugosas na margem anterior (Figs 18 e 92). Pigídio uniformemente adensado. Genitália do macho: Lobo médio sem processos laterais e com esclerito na região mediana (Fig. 147); lobos laterais do tégmen suavemente emarginados (Fig. 160) ...

Penthobruchus Kingsolver

7. Lobo pós-ocular largo (Fig. 45). Estrias elitrais distintamente pontuadas; interestrias com áreas rugosas na margem anterior (Figs 19, 20 e 93). Pigídio adensado ou em sua maior parte glabro com pequena área adensada na região mediana (Figs 30 e 31). Genitália do macho: Lobo médio com processos laterais e sem esclerito na região mediana (Fig. 148); lobos laterais do tégmen fortemente emarginados (Fig. 161) Pygiopachymerus Pic

\section{Diagnoses}

\section{Grupo Merobruchus}

Figs 3-20

Diagnose. Cabeça com carena frontal (Figs 32-42); carena lateral do pronoto obsoleta a ausente (Figs 73-75); pronoto na maioria das vezes com gibosidades (Figs 69-71, 73, 74 e 80); élitro freqüentemente com gibosidades (Figs 84, 86, 87 e 80); fêmur posterior em geral com dentículos na margem externa (ausentes em Merobruchus e Meibomeus) (Figs 117, 121, 122 e 129), sem pré-pécten (exceto Meibomeus e Caryedes) e com pécten desenvolvido, forte a moderadamente projetado (exceto Meibomeus) em geral com mais de três dentes (Figs 119 e 128).

Plantas hospedeiras. Espécies do grupo Merobruchus ocorrem nas três subfamílias de leguminosas, Mimosoideae, Papilionoideae e Caesalpinioideae (Tab. II).

\section{Merobruchus Bridwell Figs 15-17}

Diagnose. Gibosidade subasal do pronoto pouco elevada, gibosidade mediana ausente (Figs 16 e 72). Estrias do élitro nunca abreviadas, com dentes na base das estrias 3 e 4 ou 3-6 sobre gibosidade pouco elevada a moderada (Fig. 91). Pécten com 3-6 dentes, variando em espaçamento; tíbia posterior em geral reta; mucro curto ou maior que a metade da largura do ápice da tíbia (Figs 126 e 127). Quinto urosternito dos machos e fêmeas com chanfradura no ápice, mais conspícuas nas fêmeas (Fig. 137). Lobo médio curto e largo; valva ventral larga, subarredondada; saco interno freqüentemente com esclerito em 
Tabela II. Gêneros de plantas hospedeiras do grupo Merobruchus.

\begin{tabular}{|c|c|c|c|}
\hline \multirow{2}{*}{ Gêneros } & \multicolumn{3}{|c|}{ Plantas hospedeiras } \\
\hline & Mimosoideae & Papilionoideae & Caesalpinioideae \\
\hline \multirow[t]{8}{*}{ Merobruchus } & Acacia $(10)$ & & \\
\hline & Albizia (10) & & \\
\hline & Chloroleucon (= Pithecellobium) (10) & & \\
\hline & Enterolobium (10) & & \\
\hline & Lysiloma (10) & & \\
\hline & Pseudosamanea (10) & & \\
\hline & Leucaena (10) & & \\
\hline & Mimosa $(7,8)$ & & \\
\hline \multirow[t]{9}{*}{ Meibomeus } & & Adesmia (6) & \\
\hline & & Aeschynomene $(12,16,14,16)$ & \\
\hline & & Coursetia (16) & \\
\hline & & Desmodium $(6,11,14,16)$ & \\
\hline & & Indigofera (16) & \\
\hline & & Lespedeza (16) & \\
\hline & & Poiretia (6) & \\
\hline & & Rhynchosia (16) & \\
\hline & & Zornia (6) & \\
\hline \multirow[t]{10}{*}{ Caryedes } & Acacia (11) & Dioclea (4) & Bauhinia (9) \\
\hline & & Calopogonium (4) & \\
\hline & & Centrosema (4) & \\
\hline & & Canavalia (4) & \\
\hline & & Galactia (4) & \\
\hline & & Mucuna (4) & \\
\hline & & Pachyrhizus (4) & \\
\hline & & Phaseolus (4) & \\
\hline & & Rhynchosia (4) & \\
\hline & Chloroleucon (= Pithecelobium) (13) & & \\
\hline \multirow[t]{3}{*}{ Ctenocolum } & & Bergeronia (3) & \\
\hline & & Lonchocarpus $(=$ Muellera $)(3,11)$ & \\
\hline & & Piscidia $(3,11)$ & \\
\hline \multirow[t]{2}{*}{ Gibbobruchus } & & & Bauhinia $(5,11)$ \\
\hline & & & Cercis $(5,11)$ \\
\hline \multirow[t]{2}{*}{ Penthobruchus } & & & Cercidium $(2,8)$ \\
\hline & & & Parkinsonia $(2,8)$ \\
\hline \multirow[t]{2}{*}{ Pygiopachymerus } & & & Cassia $(1,8,11,15)$ \\
\hline & & & Hymenaea (8) \\
\hline
\end{tabular}


forma de "Y" invertido (Fig. 146); lobos laterais do tégmen profundamente emarginados (Figs 158 e 159).

Plantas hospedeiras. Ocorrem exclusivamente em Mimosoideae e oito gêneros pertencentes às tribos Acacieae, Ingeae e Mimoseae já foram registrados como hospedeiros (Tab. II).

\section{Meibomeus Bridwell}

(Figs 13 e 14)

Diagnose. Tegumento negro, pilosidade no élitro freqüentemente rala (Fig. 13). Gibosidade subasal do pronoto pouco elevada, gibosidade mediana geralmente ausente. Élitro freqüentemente sem gibosidade basal. Quarta estria do élitro abreviada ou não na base, com ou sem dente (Figs 88 e 89). Fêmur posterior sem dentes na margem externa, geralmente pré-pécten com 1-3 dentes; pécten em geral pouco projetado com 3-8 dentes em linha; tíbia posterior em geral reta; mucro obsoleto (Figs 123125). Primeiro urosternito freqüentemente com estreita faixa vertical glabra, lateralmente. Lobo médio em geral longo e delgado, raramente com escleritos desenvolvidos no saco interno (Figs 144 e 145); tégmen com lobos laterais suavemente emarginados e em geral encurvados apicalmente (Figs 155-157).

Plantas hospedeiras. Ocorrem exclusivamente em Papilionoideae. Nove gêneros já foram citados pertencentes a cinco tribos, Aeschynomeneae, Desmodieae, Indigofereae Phaseoleae, Robinieae, sendo o maior número de registros em Desmodium Desv. (Tab. II).

\section{Caryedes Hummel}

\section{Figs 3-7}

Diagnose. Cabeça geralmente alongada (Fig. 32). Gibosidade mediana do pronoto em geral presente e conspícua; gibosidade subasal do pronoto freqüentemente pouco elevada (Figs 69 e 73); gibosidade basal do élitro geralmente pouco elevada (Figs 3-7 e 84). Estrias elitrais sem dentes, ou com único dente na base da quarta estria em gibosidade pouco elevada ou inconspícua (Figs 84 e 85). Asa com cv conectando Cu1a a PCu (Fig. 108). Fêmur posterior com ou sem dentes na margem externa; pré-pécten presente; pécten com 3-6 dentes variando em espaçamento; tíbia posterior geralmente reta; mucro freqüentemente muito longo (Figs 117-119). Lobo médio em geral muito alongado e delgado (Fig. 138); tégmen com lobos laterais suavemente emarginados (Fig. 149).

Plantas hospedeiras. Caryedes ocorre em Mimosoideae, Papilionoideae e Caesalpinioideae, mas a maioria das plantas hospedeiras pertence à Papilionoideae, tribo Phaseoleae. Apenas cinco espécies consomem sementes de Caesalpinioideae e duas em Mimosoideae (Tab. II).

\section{Ctenocolum Kingsolver \& Whitehead Figs 8,9}

Diagnose. Gibosidade mediana do pronoto usualmente pouco elevada e subasal em geral proeminente (Figs 8, 9 e 70). Base das estrias elitrais 3, 4, algumas vezes 5 e 6 com dentes sobre gibosidade forte (Fig. 86). Asa sem veias Cu1a e cv (Fig. 109). Fêmur posterior com dentes ou dentículos na margem externa; pécten com 6-9 dentes ligeiramente espaçados após o primeiro dente, ou com 12-16 dentes projetados em fileira; tíbia posterior encurvada ou reta (Figs 120 e 121). Lobo médio em geral pouco alongado (Figs 140, 141); tégmen com lobos laterais fortemente emarginados (Figs 151 e 152).

Plantas hospedeiras. Exclusivamente Papilionoideae da tribo Millettieae, principalmente Lonchocarpus Kunth. (Tab. II).

\section{Gibbobruchus Pic \\ Figs 10-12}

Diagnose. Mola das mandíbula com dentes desenvolvidos (Fig. 58). Gibosidade mediana e subasal do pronoto freqüentemente conspícuas; gibosidade mediana geralmente dividida por sulco médio transverso (Figs 71 e 74); gibosidades basal e subasal do élitro em geral conspícuas (Figs 11, 12, 80 e 87). Asa com cv conectando Cu1a a PCu (Fig. 110). Fêmur posterior com dentes na margem externa; pécten com 3-7 dentes variando em espaçamento; tíbia posterior encurvada ou reta (Fig. 122). Pigídio das fêmeas com área glabra ampla e polida na região mediana-apical e dos machos de $G$. speculifer e $G$. ornatus (Figs 27 e 29). Tégmen com lobos laterais fortemente emarginados (Figs 153 e 154).

Plantas hospedeiras. Gibbobruchus ocorre exclusivamente em Caesalpinioideae da tribo Cercideae, principalmente Bauhinia L. (Tab. II).

\section{Penthobruchus Kingsolver}

Fig. 18

Diagnose. Gálea da maxila apenas com cerdas simples (Fig. 66). Gibosidade subasal do pronoto e basal do élitro pouco elevada (Fig. 18). Estrias elitrais formadas por pontos isolados e alinhados (Fig. 92). Asa com cv conectando $\mathrm{Cu} 1 \mathrm{a}$ a $\mathrm{PCu}$ (Fig. 115). Fêmur posterior com dentes na margem externa; pécten com 3-9 dentes variando em espaçamento; tíbia posterior fortemente encurvada e com rugosidade na margem externa (Fig. 128). Lobo médio com esclerito na região mediana (Fig. 147); tégmen com lobos laterais expandidos lateralmente e suavemente emarginados (Fig. 160).

Plantas hospedeiras. As espécies de Penthobruchus ocorrem exclusivamente em Caesalpinioideae da tribo Caesalpinieae (Tab. II).

\section{Pygiopachymerus Pic}

\section{Figs 19, 20}

Diagnose. Gálea da maxila apenas com cerdas simples (Fig. 66). Lobo pós-ocular largo (Fig. 45). Gibosidade subasal do pronoto conspícua (Figs 19 e 20). Áreas rugosas na margem anterior do élitro (Fig. 93). Asa com cv conectando Cu1a a Pcu (Fig. 116). Fêmur posterior com dentes na margem externa; pécten com 5-7 dentes variando em espaçamento; tíbia posterior fortemente encurvada e com rugosidade na margem exter- 
na (Fig. 129). Pigídio adensado ou em sua maior parte glabro com pequena área adensada na região mediana (Figs 30 e 31). Lobo médio com processos laterais e sem escleritos na região mediana (Fig. 148); tégmen com lobos laterais expandidos lateralmente e fortemente emarginados (Fig. 161).

Plantas hospedeiras. Exclusivamente Caesalpinioideae das tribos Cassieae e Deltarieae (Tab. II).

\section{Considerações}

A análise morfológica comparativa de Caryedes, Ctenocolum, Gibbobruchus, Meibomeus, Merobruchus, Penthobruchus e Pygiopachymerus permitiu a redefinição e a descrição de caracteres pela primeira vez estudados na grande maioria dos gêneros, como escultura do tegumento, asas, peças bucais, endosternitos e terminália da fêmea. Evidenciou também grande variabilidade nos caracteres em nivel genérico, sendo que a caracterização do grupo Merobruchus só pôde ser feita quando alguns caracteres são tratados em conjunto.

Gibbobruchus, Penthobruchus e Pygiopachymerus mostramse afins, como já indicado na literatura (Fig. 1), e provavelmente formam um grupo monofilético (Gibbobruchus), caracterizado pelo consumo de sementes de Caesalpinioideae (Tab. II). Esse grupo compartilha a presença de amplas áreas glabras nos urosternitos, uma possível sinapomorfia. Estados de caracteres como cabeça com sulco transverso obsoleto, gálea com cerdas simples, sulco ventral do fêmur posterior glabro e tíbia posterior fortemente encurvada, sem carena látero-ventral e com margem externa rugosa, podem indicar Penthobruchus como grupo-irmão de Pygiopachymerus.

Com relação a Caryedes, Meibomeus e Ctenocolum, que foram reunidos no grupo Caryedes (Fig. 1), levanta-se a hipótese que esse agrupamento não seja monofilético, mesmo sem uma análise cladística (Fig. 2). Considerando a análise de caracteres, Caryedes, Ctenocolum, Gibbobruchus, Penthobruchus e Pygiopachymerus apresentam maior proximidade entre si, compartilhando gibosidades em geral conspícuas no pronoto e élitros, fêmur posterior em geral com margem externa serreada, pécten freqüentemente com maior número de dentes e mucro desenvolvido. Merobruchus e Meibomeus são mais distintos. Compartilham o disco do pronoto com fovéolas uniformemente distribuídas, gibosidades no pronoto e élitros usualmente ausentes ou quando muito pouco elevadas, inconspícuas, fêmur posterior com margem externa não serreada, pécten geralmente com número reduzido de dentes, tíbia posterior usualmente reta e mucro curto. Vários desses caracteres ocorrem em outros gêneros de Acanthoscelidina e possivelmente não indicam íntima relação de parentesco entre eles.

Meibomeus e Ctenocolum alimentam-se exclusivamente de sementes de Papilionoidea. No entanto, Caryedes, além de consumir Papilionoideae, alimenta-se de Mimosoideae e Caesalpinioideae. Em Mimosoideae, compartilha com Merobruchus, Acacia Mill. e Chloroleucon (Benth.) Britton \& Rose e, em Caesalpinioideae, compartilha com Gibbobruchus, Bauhinia L. (Tab. II). Esses dados, além dos morfológicos, são mais um indicativo do provável parafiletismo do grupo Caryedes (Fig. 2).

Com a análise morfológica, novas estruturas são apontadas como de relevância e poderão ser utilizadas em futuros estudos taxonômicos e cladísticos em Acanthoscelidina. No caso do grupo Merobruchus, torna-se imprescindível a realização de análises cladísticas para testar seu monofiletismo, assim como, também verificar relações de parentesco entre os gêneros.

\section{AGRADECIMENTOS}

Aos pesquisadores J.M. Kingsolver (Florida State Collections of Arthropods, Gainesville, Fla) e C.D. Johnson (in memorian) pela doação de exemplares, envio de bibliografia e apoio constante; aos curadores das instituições pelo empréstimo do material; ao Centro de Microscopia Eletrônica da Universidade Federal do Paraná pelas micrografias e ao Conselho Nacional de Desenvolvimento Científico e Tecnológico pela concessão das bolsas. Esta é a contribuição número 1745 do Departamento de Zoologia, Universidade Federal do Paraná.

\section{LITERATURA CITADA}

Borowiec, L. 1987. The genera of seed beetles (Coleoptera, Bruchidae). Polskie Pismo Entomologiczne 57: 3-207.

BRIDWELl, J.C. 1946. The genera of the beetles of the family Bruchidae in America north of Mexico. Journal of the Washington Academy of Sciences 36: 52-57.

Crowson, R.A. 1944. Futher studies on the metendosternite in Coleoptera. Transactions of the Royal Entomological Society of London 94 (2): 273-310.

Crowson, R.A. 1955. The natural classification of the families of Coleoptera. London, Nathanial Lloyd, 214p.

Daviault, L. 1928. Sur le développement post-embryonnaire de la bruche du harricot: Acanthoscelides obtectus Say. Suivi de considérations sur la signification phylétique de son dimorphisme larvaire. Annales de la Société Entomologique de France 97: 105-132.

Johnson, C.D. 1990. Systematics of the seed beetle genus Acanthoscelides (Coleoptera: Bruchidae) of Northern of South America. Transactions of the American Entomological Society (116): 297-618.

Johnson, C.D. \& J. Romero. 2004. A review of evolution of oviposition guilds in the Bruchidae (Coleoptera). Revista Brasileira de Entomologia 48 (3): 401-408.

Johnson, C.D. \& J.M. Kingsolver. 1973. Revision of the genus Sennius Bridwell, 1946 (Coleoptera: Bruchidae). United States Department of Agriculture, Technical Bulletin 1462: 1-135.

Johnson, C.D.; B.J. Souhtgate \& A. Delobel. 2004. A revision of the Caryedontini (Coleoptera: Bruchidae: Pachymerinae) of Africa and the middle east. Memoirs of the American Entomological Society 44: 1-120.

Kingsolver, J.M. 1964. The genus Neltumius (Coleoptera: Bruchidae). The Coleopterists Bulletin 18: 105-111.

Kingsolver, J.M. 1970. Synopsis of the genus Pygiopachymerus Pic with notes on its relationships to other genera (Coleop- 
tera: Bruchidae: Bruchinae). Proceedings of the Entomological Society of Washington 72: 37-42.

Kingsolver, J.M. 1973. Description of a new genus and a new species of Bruchidae from South America (Coleoptera). Journal of Washington Academy of Science 63: 142-146.

Kingsolver, J.M. 1980. Eighteen new species of Bruchidae, principally from Costa Rica, with host records and distributional notes (Insecta: Coleoptera). Proceedings of the Biological Society of Washington 93: 229-283.

Kingsolver, J.M. 1987. Six new species of Bruchidae (Coleoptera) from Venezuela and Brazil with notes on a brazilian pest of stored pigeons peas. Experientiae 30 (5): 57-79.

Kingsolver, J.M. 1988. Systematics of the genus Merobruchus of Continental North America and the West Indies (Coleoptera: Bruchidae). United States Department of Agriculture, Technical Bulletin 1744: 1-63.

KINGSOLVER, J.M. 2004. Handbook of the Bruchidae of the United States and Canada (Insecta, Coleoptera). Vol. 1. United States Department of Agriculture Technical Bulletin 1912: 1-324.

Kingsolver, J.M. \& G.S. Pfaffenberger. 1980. Systematic position of the genus Rhaebus (Coleoptera: Bruchinae). Proceedings of the Entomological Society of America 82 (2): 293-311.

Kingsolver, J.M. \& D.R. WhiteHEAD. 1974a. Biosystematics of Central American species of Ctenocolum (Coleoptera: Bruchidae). Proceedings of the Biological Society of Washington 87: 283-312.

Kingsolver, J.M. \& D.R. Whitehead. 1974b. Classification and comparative biology of the seed beetle genus Caryedes Hummel (Coleoptera: Bruchidae). Transactions of the American Entomological Society 100: 341-436.

Kingsolver, J.M. \& D.R. WhitehEAD. 1976. The North and Central American species of Meibomeus (Coleoptera: Bruchidae: Bruchinae). United States Department of Agriculture, Technical Bulletin 1523: 1-54.

MaCÊDo, M.V.; T.M. Lewinsohn \& J.M. Kingsolver. 1992. New host records of some bruchid species in Brazil with the description of a new species of Caryedes (Coleoptera: Bruchidae). The Coleopterists Bulletin 46 (4): 330-336.

Maes, J. \& J.M. Kingsolver. 1991. Catalogo de los Bruchidae (Coleoptera) de Nicaragua. Revista Nicaraguense de Entomologia 16: 21-34.

Marin, D.A. \& J.M. Kingsolver. 1997. A preliminary list of the Bruchidae (Coleoptera) of Cuba. Entomological News 108 (3): 215-221.

Mathur, P.N. \& R.K. Dhadial. 1963. Morphology of the head capsule and mouth parts of Caryedes gonagra Fabricius (Coleoptera: Bruchidae). Proceedings of the Entomological Society of Washington 65 (4): 265-273.

Nilsson, J.A. \& C.D. Johnson 1993. A taxonomic revision of the palm bruchids (Pachymerini) and a description of the world genera of Pachymerinae. Memoirs of the American Entomological Society 41: 1-104p.

Ribeiro-Costa, C.S. 1998. Descrições de oito novas espécies bra- sileiras de Amblycerus Thunberg (Coleoptera, Bruchidae). Revista Brasileira de Zoologia 14 (3): 629-648. [1997].

Ribeiro-Costa, C.S. \& A.S. Costa. 2002. Comportamento de oviposição de Bruchidae (Coleoptera) predadores de sementes de Cassia leptophyla Vogel (Caesalpinaceae), morfologia dos ovos e descrição de uma nova espécie. Revista Brasileira de Zoologia 19 (Supl. 1): 305-316.

Ribeiro-Costa, C.S. \& J.A.P. Silva. 2003. Morphology of the adult Meibomeus cyanipennis (Sharp) (Coleoptera: Bruchidae). The Coleopterists Bulletin 57 (3): 297-309.

Romero, J. \& C.D. Johnson. 2002. Five new species of Meibomeus Bridwell from the New World with host records for them and six named species (Coleoptera: Bruchidae). The Coleopterists Bulletin 56 (3): 182-202.

Romero, J.N. \& C.D. Johnson. 2003a. Revision of the genus Neltumius Bridwell (Coleoptera: Bruchidae). The Coleopterists Bulletin 57 (2): 219-236.

Romero, J.N. \& C.D. Johnson. 2003b. Meganeltumius juani, new genus, new species (Coleoptera: Bruchidae). The Coleopterists Bulletin 57 (2): 237-242.

Romero, J.N. \& C.D. Johnson. 2004. Checklist of the Bruchidae (Insecta: Coleoptera) of Mexico. The Coleopterists Bulletin 58 (4): 613-635.

Silva, J.A.P. \& C.S. Ribeiro-Costa. 2001. Revisão das espécies sulamericanas de Meibomeus Bridwell, 1946 (Coleoptera: BRUCHIDAE). Revista Brasileira de Entomologia 45: 305-324.

Silva, J.A.P.; C.S. Ribeiro-Costa \& C.D. Johnson. 2003. Sennius Bridwell (Coleoptera, Bruchidae): novas espécies predadores de sementes de Chamaecrista Moench (Caesalpinaceae) da Serra do Cipó, Santana do Riacho, Minas Gerais, Brasil. Revista Brasileira de Zoologia 20 (2): 269-277.

SINGH, T. 1981a. A taxonomic study of the wing of Bruchidae (Coleoptera). Oriental Insects 15 (2): 221-225.

SingH, T. 1981b. Morphology and musculature of the head capsule and mouth parts of Callosobruchus chinensis (L.) (Coleoptera, Bruchidae). Indian Zoologist 5 (1-2): 97-102.

SingH, T. 1986. A taxonomic study on the head appendages of adult Bruchidae (Coleoptera). Uttar Pradesh Journal of Zoology 6 (1): 52-57.

TERÁN, A.L. 1962. Observaciones sobre Bruchidae (Coleoptera) del Noroeste Argentino. Acta Zoologica Lilloana 18: 211-243.

Terán, A.L. \& J.M. Kingsolver. 1977. Revision del genera Megacerus (Coleoptera: Bruchidae). Opera Lilloana 25: 1-287.

UdAYAgiRI, S. \& S.R. WADHI. 1989. Catalog of Bruchidae. Memoirs of the American Entomological Institute 45: 84-87.

WhiteHEAD, D.R. \& J.M. KINGSOLVER. 1975. Biosystematics of the North and Central American species of Gibbobruchus (Coleoptera: Bruchidae: Bruchinae). Transactions of the American Entomological Society 101. 167-225.

Submitted: 25.IV.2008; Accepted: 08.XII.2008.

Editorial responsibility: Gabriel L. Figueira Mejdalani 